\title{
Geosynthetic-Reinforced Soil Structures for Railways in Japan
}

\author{
Fumio Tatsuoka $\cdot$ Masaru Tateyama \\ Junichi Koseki • Toyoji Yonezawa
}

Accepted: 16 December 2013 / Published online: 12 February 2014

(C) Springer New York 2014

\begin{abstract}
Geosynthetic-reinforced soil retaining walls (GRS RWs) have been constructed for a total length of about $150 \mathrm{~km}$ as of June 2013 mainly for railways, including highspeed train lines. After a full-height wrapped-around GRS wall has been constructed and the major residual deformation of the backfill and supporting ground has taken place, a full-height rigid (FHR) facing is constructed by casting-in-place concrete on wrappedaround wall face in such that it is firmly connected to the reinforcement layers. A number of this type GRS RWs performed very well during the 1995 Great Kobe and the 2011 Great East Japan Earthquakes. The seismic design code for railway soil structures has been revised taking into account such high-level seismic loads as experienced during the 1995 Kobe EQ. A number of conventional-type RWs and embankments collapsed during these and other earthquakes, heavy rains, floods, and storm wave actions. Many of them were reconstructed to this type GRS RWs and geosynthetic-reinforced embankments. Among a couple of new bridge types that have been developed, GRS integral bridge comprises a continuous girder of which both ends are structurally integrated without using bearings to the top of the facings of a pair of GRS RWs. The first prototype was constructed for a high-speed train line in 2011 and three more were constructed to restore bridges that fully collapsed by great tsunami during the 2011 Great East Japan EQ.
\end{abstract}

Keywords Earthquake $\cdot$ Flood $\cdot$ Geosynthetics-reinforced soil retaining wall $\cdot$ GRS integral bridge $\cdot$ High-speed train $\cdot$ Tsunami

\footnotetext{
F. Tatsuoka $(\bowtie)$

Department of Civil Engineering, Tokyo University of Science, Tokyo, Japan

e-mail: tatsuoka@sepia.ocn.ne.jp
}

\section{Tateyama}

Structural Engineering Division, Railway Technical Research Institute, Tokyo, Japan

J. Koseki

Institute of Industrial Science, The University of Tokyo, Tokyo, Japan

T. Yonezawa

Hokkaido Shinkansen Construction Bureau, Japan Railway Construction, Transport and Technology

Agency, Yokohama, Japan 


\section{Introduction}

The design and construction policy of soil structures for Japanese railways was drastically revised during the last 25 years, after the 1995 Great Kobe Earthquake, as follows:

1. The standard type of retaining wall (RW) has fully changed from the conventional cantilever RW to the geosynthetic-reinforced soil (GRS) RW having staged constructed full-height rigid (FHR) facing with a strong connection between the facing and the reinforcement layers (Fig. 1a; [1, 2]). The GRS RWs of this type have been constructed for a total length of about $150 \mathrm{~km}$ (as of June 2013) mainly for railways, including high-speed train lines. Figure 2 shows a typical case.

2. It has also become the standard practice to reconstruct conventional-type embankments and RWs that collapsed by earthquakes, heavy rains, and floods to this type GRS RWs.

3. A couple of new bridge systems using the GRS technology were developed and have been replacing the conventional-type bridges. With GRS bridge abutments, a girder is placed via bearings on the top of the facing of GRS RW [3, 4]. About 50 GRS abutments of this type have been constructed. The latest bridge type is the one called the GRS integral bridge [5-8], which comprises both ends of a continuous girder that are structurally integrated without using bearings to the facings of a pair of GRS RWs described in Fig. 1. The first GRS integral bridge was constructed 2012 for a high-speed train line and three others were constructed in 2013.

4. These GRS structures were and will be extensively used for the construction of high-speed train lines [9], which is among the most critical and important infrastructures in Japan.

5. Soil structures are now designed against very high seismic loads (called level 2 design seismic load) as experienced during the 1995 Great Kobe Earthquake, in the similar way as RC and metal structures [10-14].

So far, no problematic case has taken place with all these GRS structures. Having experienced the 1995 Great Kobe, the 2011 Great East Japan Earthquakes and others and many times of heavy rains and floods, it has been proven that these GRS technologies are very cost-effective, in particular by having very high resistance against these severe types of natural disaster.

Most recently, various types of GRS structure were densely constructed for a new high-speed train line, called Hokkaido Shinkansen (Fig. 3a; $[15,16])$. The construction started in 2005 and will end by the end of 2014. At many sites within a length of $37.6 \mathrm{~km}$ between Kikonai and Shin-Hakodate Stations (Fig. 3b), the following various types of GRS structure were constructed:

1. GRS RWs having FHR facing (at sites denoted by R in Fig. 3b) for a total length of $3.5 \mathrm{~km}$ with the largest wall height of $11 \mathrm{~m}$, while no conventional-type cantilever RW was constructed.

2. In total 29 GRS bridge abutments (denoted by A), while no conventional-type bridge abutment was constructed. The tallest one is $13.4 \mathrm{~m}$ high. 
a

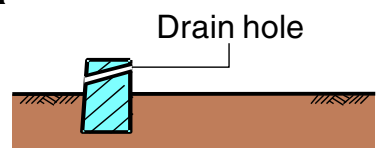

1) Leveling pad for facing

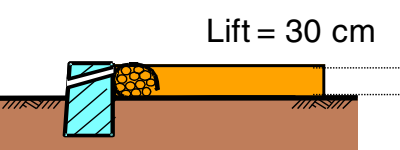

3) Backfilling \& compaction

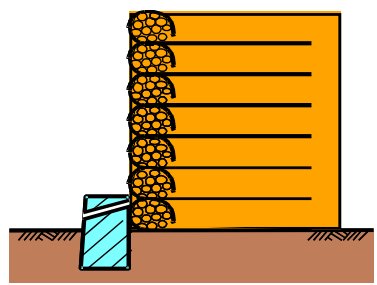

5) Completion of wrapped-around wall

2) Placing geosynthetic \&

See b) gravel gabions

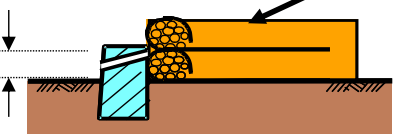

4) Second layer

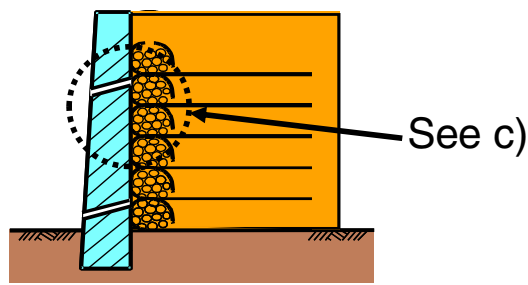

6) Casting-in-place $\mathrm{RC}$ facing

b

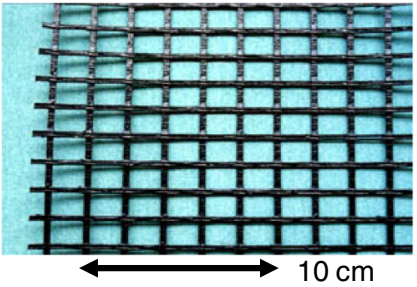

Typical polymer geogrid

C

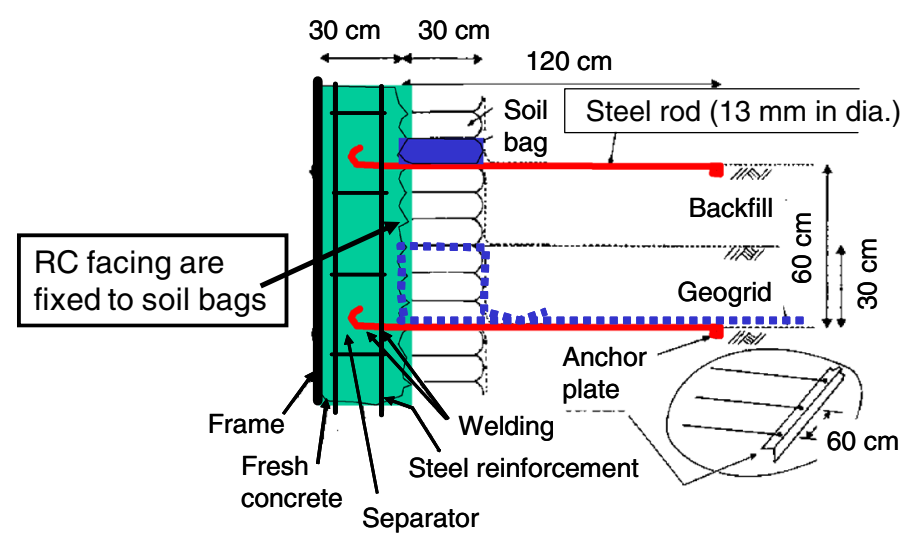

Fig. 1 GRS RW with FHR facing: a staged construction procedure; $\mathbf{b}$ a typical geogrid; and $\mathbf{c}$ facing construction [1] 


\section{a}

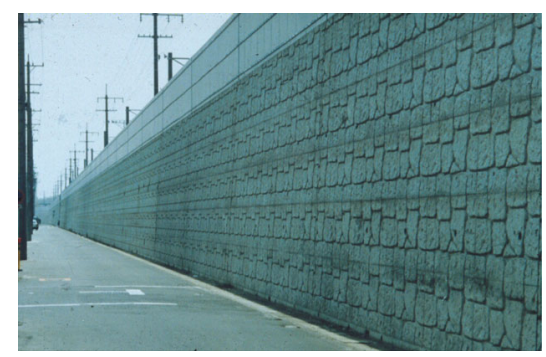

b

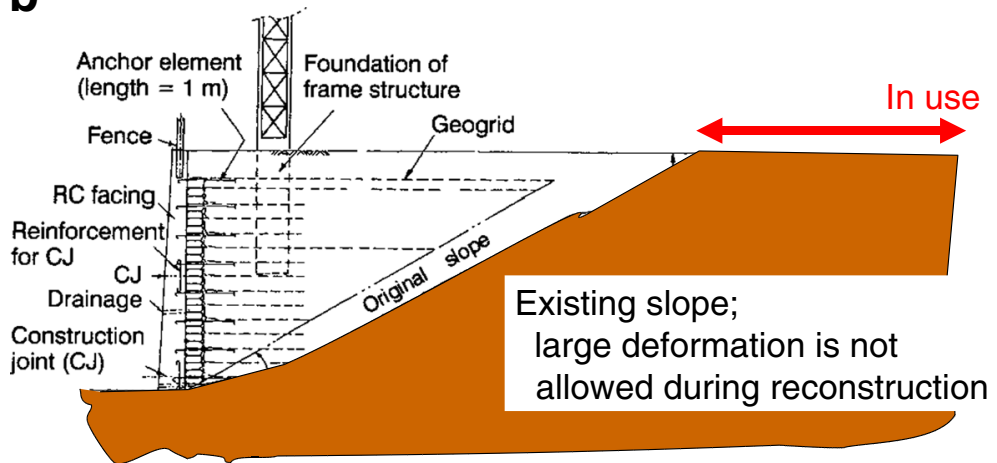

Fig. 2 Reconstruction of slopes of an existing embankment to a vertical wall for a high-speed train yard, 1990-1991, Biwajima, Nagoya: average height, $5 \mathrm{~m}$ and total length, $930 \mathrm{~m}$ : a a view in 1991; b a typical cross section [1]

3. A GRS integral bridge (denoted by I) at Kikonai, which is the first prototype of this new bridge type.

4. Three GRS Box Culverts to accommodate local roads under-passing the railway (denoted by B). Each RC box structure is integrated to GRS RWs at both sides. The tallest one is $8.4 \mathrm{~m}$ high.

5. Eleven GRS Tunnel Entrance Protections (denoted by T). A GRS arch structure stabilizes the slope immediately above the tunnel entrance to protect trains against falling rocks and sliding soil masses. The tallest one is $12.5 \mathrm{~m}$ high.

Figure 4 shows GRS RWs with FHR facing, together with a GRS Box Culvert and a GRS Tunnel Entrance Protection, which are typical of the GRS structures for Hokkaido Shinkansen. These GRS structures were chosen because of their very high costeffectiveness: i.e., compared with conventional types, they need a lower construction and maintenance cost with a higher functionality including a higher seismic stability. In particular with GRS bridge abutments, GRS integral bridges and GRS box culverts, the settlement in the backfill immediately behind the facing (i.e., the bump) by long-term train loads and seismic loads becomes negligible, unlike the conventional-type structures. 
a

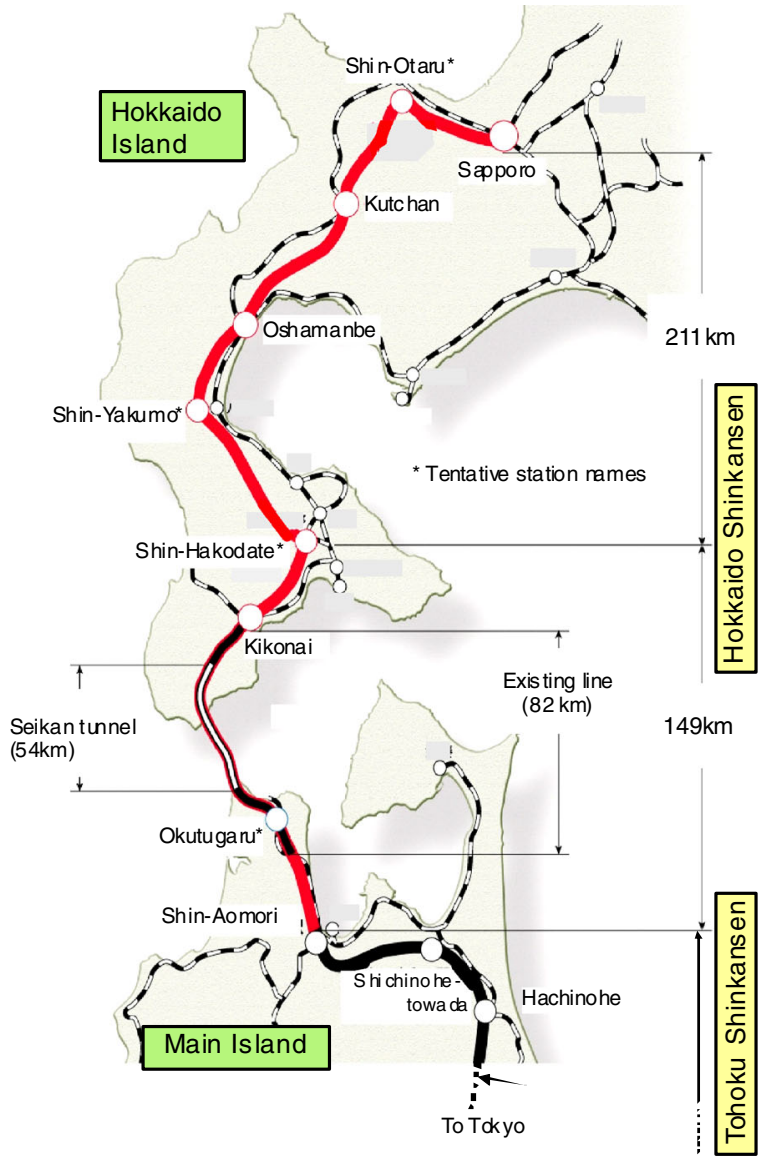

b

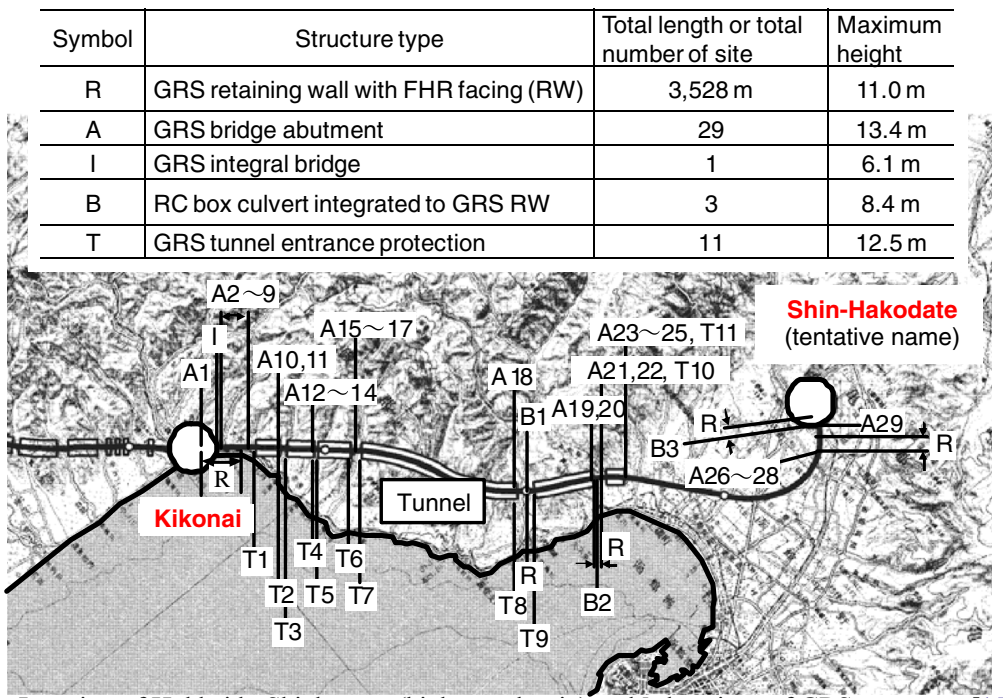

Fig. 3 a Location of Hokkaido Shinkansen (high-speed train) and b locations of GRS structures [15, 16] 
Fig. 4 A view at stage 6 in Fig. 1a of GRS RWs at both sides of a box culvert, site B2 in Fig. 3b, Hokkaido High Speed Line $[15,16]$

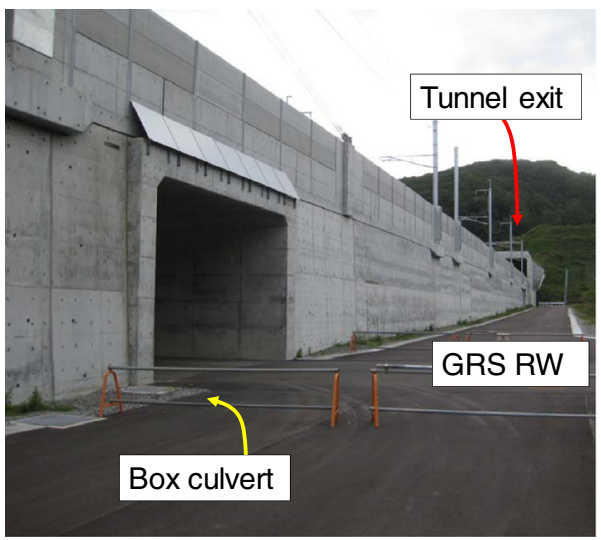

In this paper, the lessons from experiences with these GRS structures gained during the last 25 years and the essence of the new seismic design method are summarized, substantially extending the previous report [17].

\section{GRS RW with FHR Facing}

\section{Staged Construction}

After the major part of the residual deformation of the subsoil and the backfill due to the construction of geosynthetic-reinforced backfill has taken place, as shown in Fig. 1a, FHR facing is constructed by casting-in-place concrete in the space between the outer concrete frame, which is temporarily supported by steel bars anchored in the backfill, and the wall face of the GRS wall wrapped-around with geogrid reinforcement [1]). The facing and the reinforcement layers are firmly connected to each other because fresh concrete can easily enter the gravel-filled gravel bags through the aperture of the geogrid wrapping-around gravel bags that is part of the main reinforcement layer. Figure $1 \mathrm{~b}$ shows a typical type of geogrid. As the geogrid is directly in contact with fresh concrete exhibiting strong alkaline properties, a geogrid made of polyvinyl alcohol, which is known to have high resistance against high alkali environment, is usually used. Besides, extra water from fresh concrete is absorbed by the gravel bags, which reduces the negative bleeding phenomenon of concrete. By this staged construction procedure, the connection between the reinforcement and the FHR facing is not damaged by differential settlement between them that may take place if the FHR facing is constructed prior to the construction of geosynthetic-reinforced backfill. In addition, before the construction of FHR facing, the backfill immediately behind the wall face can be well compacted.

Before the construction of FHR facing, the gravel bags piled at the wall face function as a temporary but stable facing resisting against earth pressure generated by backfill compaction and the weight of overlying backfill. Besides, with the help of these gravel bags, backfill compaction becomes efficient. For completed GRS RWs, the 
gravel bags function as a drainage and as a buffer protecting the connection between the FHR facing and the reinforcement against potential relative vertical and horizontal displacements. Moreover, to construct a conventional-type cantilever RC RW, concrete forms supported by a propping system are necessary on both sides of the facing and they become more costly at an increasing rate with an increase in the wall height. With this type of GRS RW, on the other hand, only an external concrete form, temporarily supported with steel rods anchored in the backfill, is necessary without using any external propping and an internal concrete form supported by another propping system (Fig. 1c).

\section{Roles of Full-Height Rigid Facing}

If the wall face is loosely wrapped-around with geogrid reinforcement without using a pile of gravel bags (or their equivalent), or if the reinforcement layers are not connected to a rigid facing, no or only very low lateral earth pressure is activated at the wall face (Fig. 5a). Then, the stiffness and strength of the active zone becomes low, which may lead to intolerably large deformation, or even collapse in extreme cases, of the active zone. On the other hand, with this GRS RW system, before the construction of FHR facing, the gravel bags function as a temporary stable facing; therefore, high earth pressure can be activated at the wall face (Fig. 5b). This high earth pressure is transferred to the FHR facing upon its construction, which results in high confining pressure at the wall face, thus high stiffness and strength of the active zone, then, high performance of the wall. This mechanism is particularly important to ensure high seismic stability.

A conventional-type RW is a cantilever structure resisting the active earth pressure from the unreinforced backfill. Therefore, large internal moment and shear forces are mobilized in the facing while large overturning moment and lateral thrust force develops at the base of the facing. Thus, a pile foundation usually becomes necessary, in particularly when constructed on thick soft subsoil. These disadvantages become more serious at an increasing rate with an increase in the wall height. In contrast, as the FHR facing of this GRS RW system is a continuous beam supported by many reinforcement layers with a small span (i.e., $30 \mathrm{~cm}$ ), only small forces are mobilized in the FHR facing even by high earth pressure. Hence, the FHR facing becomes much simpler and lighter than conventional cantilever RC RWs. Besides, as only small overturning moment and lateral thrust force is activated at the facing bottom, a pile

a

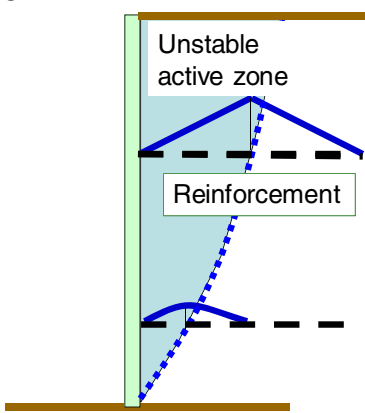

No connection strength b

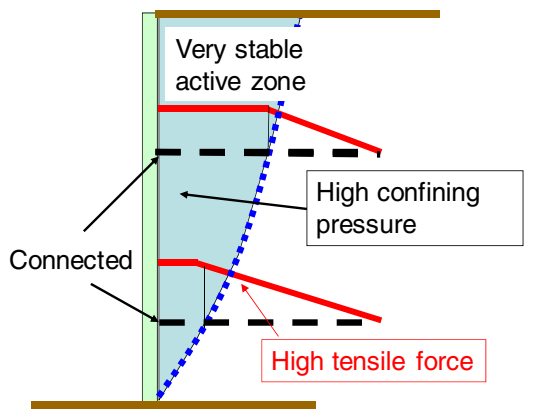

High connection strength

Fig. 5 Importance of firm connection between the reinforcement and the rigid facing for wall stability [39] 
foundation is not used in usual cases. If constructed on relatively soft ground, usually shallow ground improvement by cement-mixing is performed to ensure sufficient bearing capacity. These features make the GRS RW with FHR facing much more cost-effective (i.e., much lower construction and maintenance cost and much speedy construction using much lighter construction machines despite higher stability) than cantilever-type RC RWs. These features of the FHR facing become more important when concentrated external load is activated to the top of the facing or the crest of the backfill immediately behind the facing. The load is distributed to large part of FHR facing then to many reinforcement layers, thereby resisted by a large mass of the wall. FHR facing is often used as the foundation for electric poles (typically one pole per $50 \mathrm{~m}$ ) and noise barrier walls. GRS bridge abutment and GRS integral bridge were developed by taking advantage of this mechanism. In that case, a negligible bump develops immediately behind the FHR facing constructed as the bridge abutment, which is among the very important advantages. In comparison, reinforced soil RWs having discrete panel facing lack such a structural integrality as above, exhibiting much lower resistance against concentrated load. Besides, local failure of the facing (such as loss of a single panel) may result in the collapse of the whole wall.

\section{A Brief History of GRS RW with FHR Facing}

Until today (June 2013), GRS RWs with FHR facing have been constructed for a total length of about $150 \mathrm{~km}$ at 982 sites, mainly for railways and many for high-speed train lines (Fig. 6; [9]). No problematic case during construction as well as during long-term service has been reported. In urban areas, near vertical RWs have significant advantages over conventional gentle-sloped embankments as railway structures because of the following: (a) more stable behavior with smaller residual displacements; (b) much smaller base areas, which significantly reduces the cost for land acquisition; (c) no need for barrier walls, protection work, vegetation, and long-term maintenance of the embankment slope; and (d) a much smaller volume of ground improvement of soft sublayer if required. For these reasons, a great number of conventional-type RWs (unreinforced concrete gravity type or RC cantilever type) had been constructed in urban areas. On the other hand, at country sides, conventional gentle-sloped embankments are usually constructed due to a high construction cost of conventional-type RWs, in particular when long piles are necessary. On the other hand, it is much more cost-effective to construct GRS RW with FHR facing not only in urban areas but also at country sides, typically in the Hokkaido Shinkansen project (Fig. 3).

RC slabs for ballast-less tracks are basically free from long-term maintenance works, while conventional ballasted tracks need continuous maintenance works, which is now becoming very costly. RC slabs for ballast-less tracks are not allowed to be constructed on conventional embankments having gentle slopes or those supported by conventional-type retaining walls, as very small tolerable residual settlement of RC slabs for ballast-less tracks cannot be ensured. Instead, RC slabs for ballast-less tracks have been constructed on the backfill supported by the GRS RWs with FHR facing. Until today, no problematic case with track maintenance has been reported with all the GRS RWs with FHR facing. 
Fig. 6 a Locations of GRS RWs with a staged-constructed FHR facing as of June 2013 (locations denoted by letters $A, B$, and $\mathrm{C}$ are explained later in this paper) and b annual and cumulative wall lengths

\section{a}

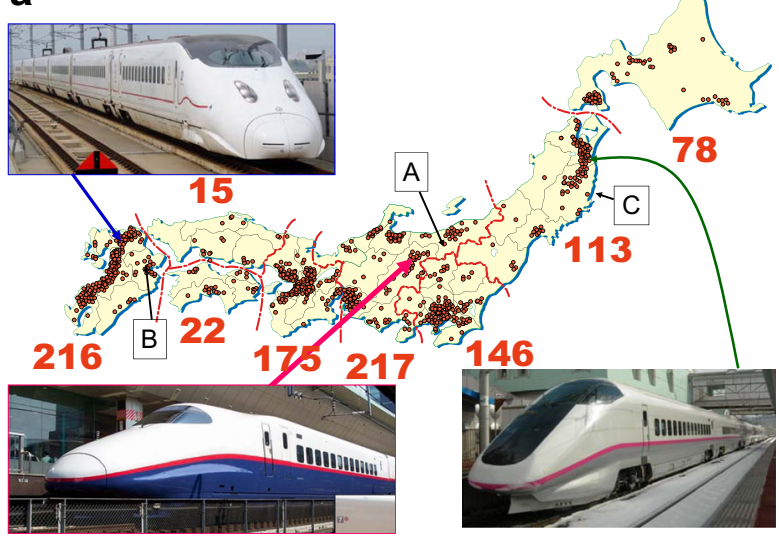

b

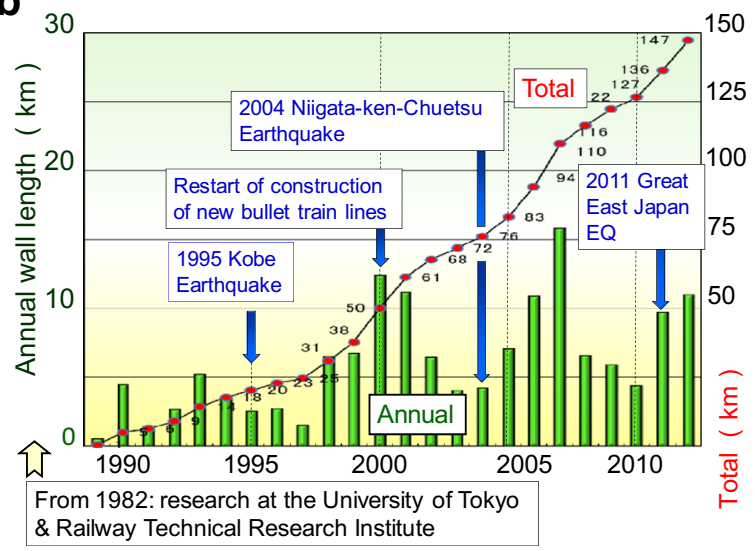

\section{Seismic Design}

A number of conventional-type RWs collapsed during the 1995 Great Kobe Earthquake. Figure 7 shows typical collapsed gravity type RWs. They were constructed about 85 years ago based on the pseudo-static seismic design at that time using a horizontal seismic coefficient of 0.2 . The walls failed in the over-turning mode by seismic loads that were much higher than the design value. In contrast, the GRS RW with FHR facing (Fig. 1) exhibited a very high seismic stability during the 1995 Great Kobe Earthquake, as typically seen from Fig. 8. This GRS RW was constructed in 1992, so it was designed before the 1995 Great Kobe earthquake based on the pseudostatic limit equilibrium stability analysis [18] requiring a minimum safety factor in terms of horizontal earth pressure equal to 1.5 against a horizontal seismic coefficient $k_{\mathrm{h}}$ equal to 0.2 . This safety factor comprises a safety factor equal to 1.25 for the global structural equilibrium times a safety factor for the tensile rupture failure of geogrid equal to 1.25 (i.e., 1.25 times 1.25 equal to 1.5 ).

This good seismic performance of the GRS RW despite that the actual seismic load was much higher is due likely to a sufficient amount of redundancy that was implicitly 
Fig. 7 Typical damage to gravity-type unreinforced concrete RWs (without a pile foundation), Ishiyagawa Station, Hanshin Railway during the 1995 Great Kobe Earthquake: a sketch of typical section; and $\mathbf{b}$ and $\mathbf{c}$ typical damaged sections on the opposite sides of the embankment

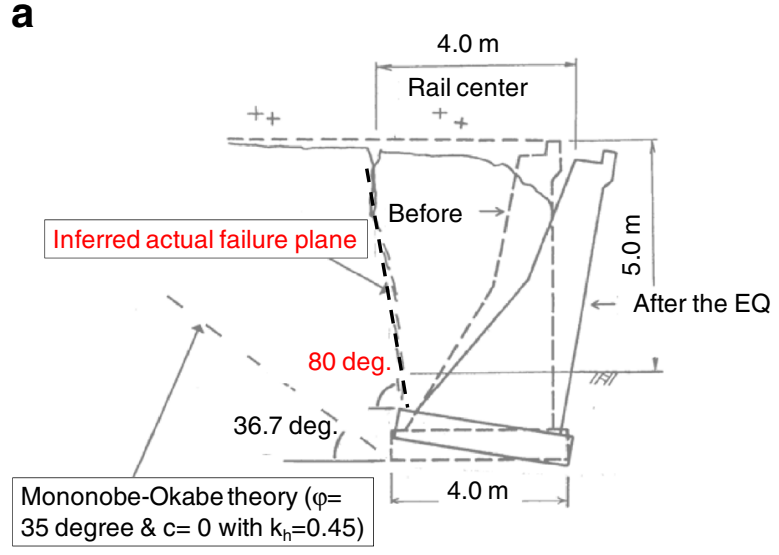

b
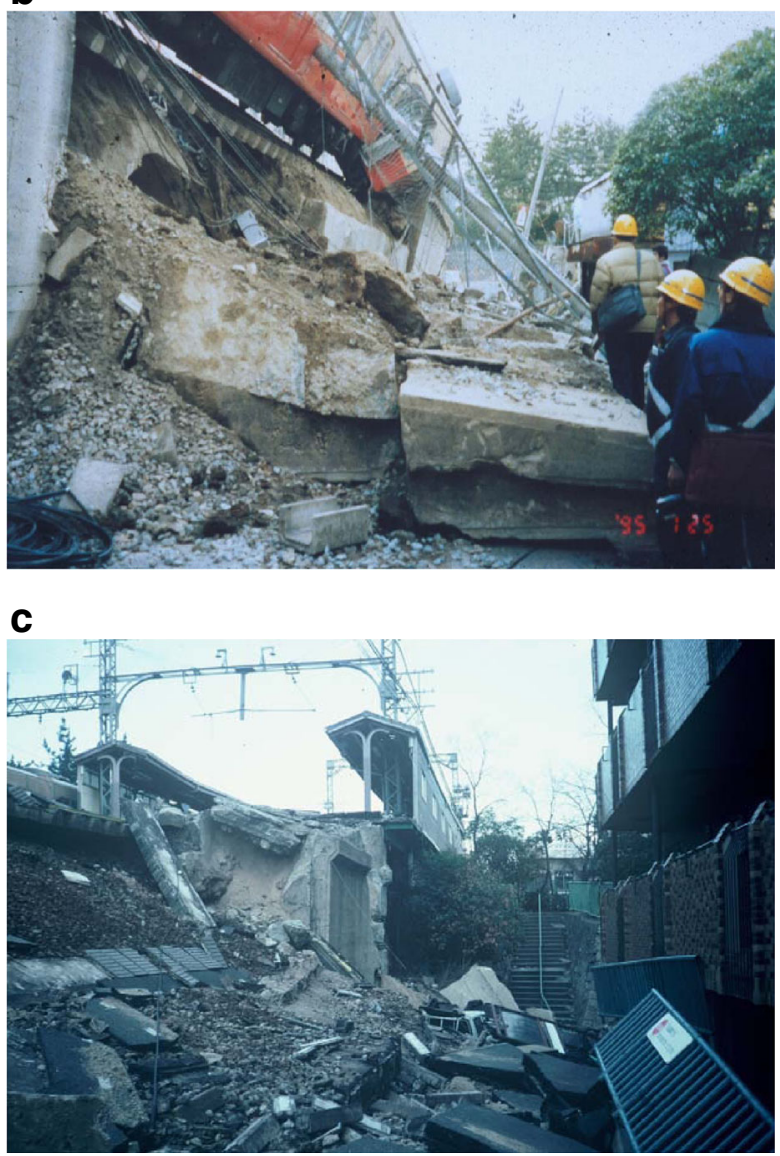

included in the design of this wall, as discussed later in this paper. A high seismic stability of the GRS RWs of this type was reconfirmed by many similar cases during the 2011 Great East Japan Earthquake (Fig. 9; [9]). Based on these experiences, a 
Fig. 8 A GRS RW having FHR facing at Tanata, Kobe City [1, 13]): a typical cross section; and $\mathbf{b}$ and $\mathbf{c}$ views of the wall 1 week after the earthquake a
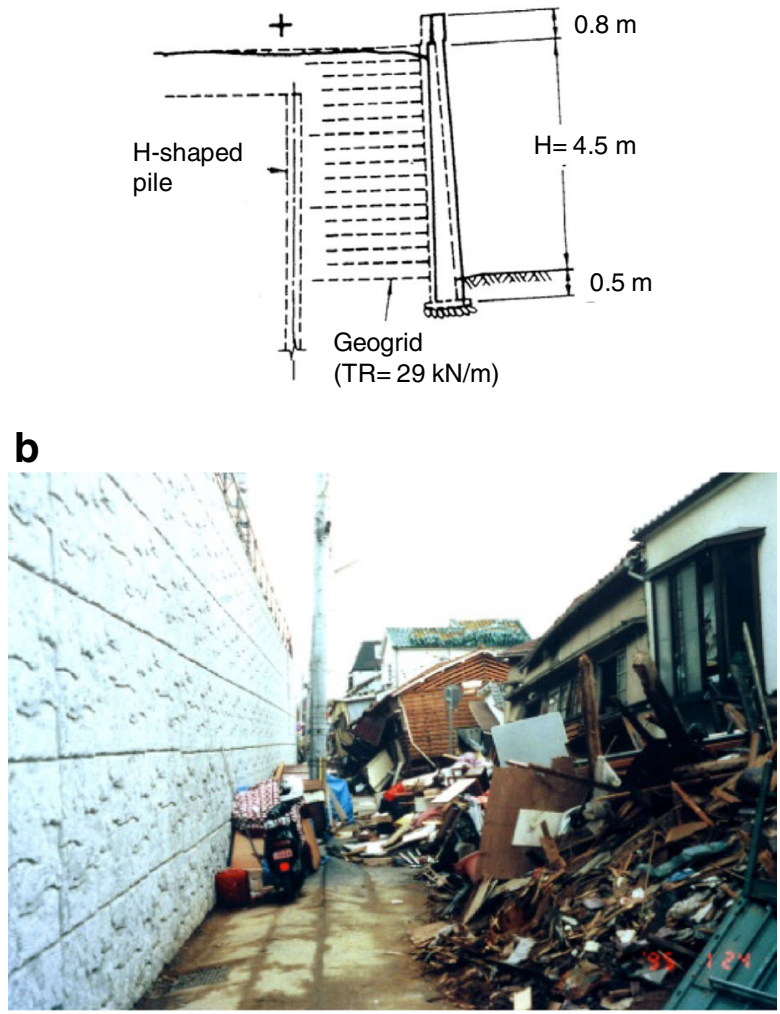

C

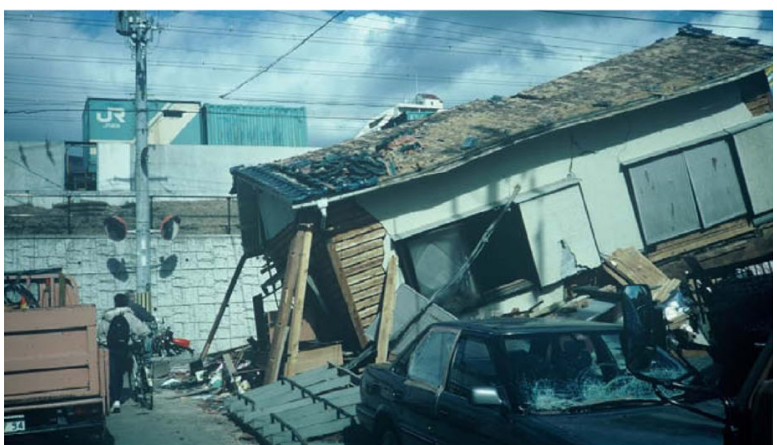

number of conventional-type RWs and embankments that collapsed by the 1995 Great Kobe Earthquake, the 2011 Great East Japan Earthquake and others, as well as those that collapsed by heavy rains, floods, and an ocean wave action during typhoon, were reconstructed to this type GRS RWs. Some recent case histories are described later in this paper.

The seismic design code of railway soil structures, including GRS structures, was substantially revised based on lessons learned from the performance of soil structures during the 1995 Great Kobe Earthquake [10, 12, 14, 19, 20]. Since then, the code has 


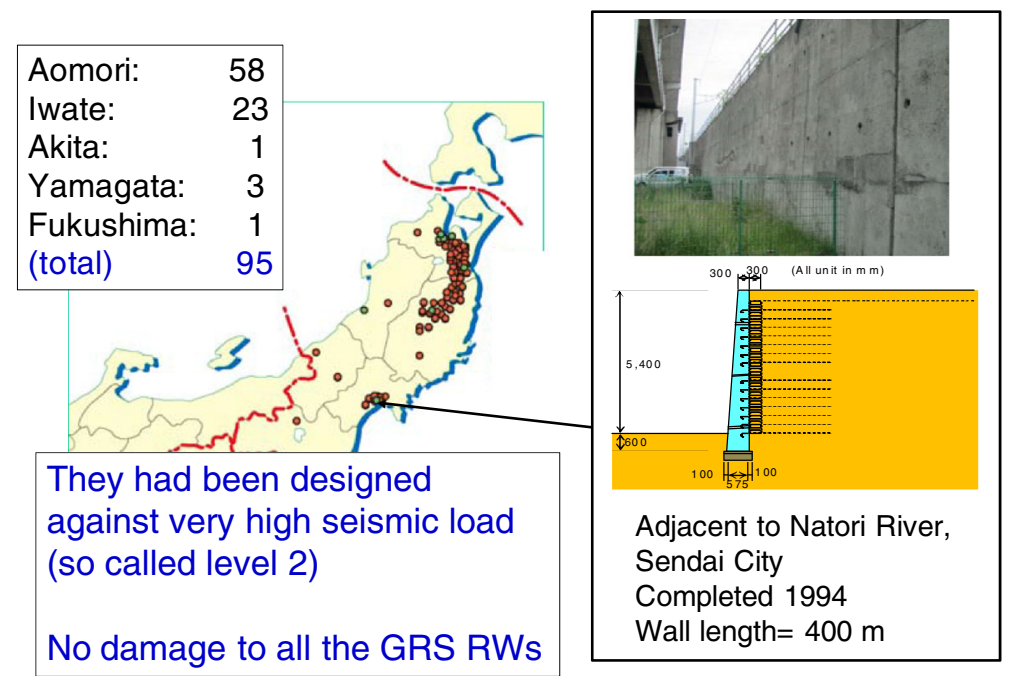

Fig. 9 High performance of GRS RWs with FHR facing for railways, including high-speed trains, constructed before the 2011 Great East Japan Earthquake

been consistently revised referring to new lessons from subsequent earthquakes. The latest version of Design Standard for Railway Soil-Retaining Structures (edited by Railway Technical Research Institute) was published in 2012. The new seismic design code has several characteristic and unique features including the following.

Firstly, according to the importance level of concerned structures, three ranks of required seismic performance are introduced in the same way as the other civil engineering structures (Table 1): e.g.,

1. Soil structures supporting RC slabs for ballast-less tracks of high speed train lines are required rank I;

2. Those supporting ballasted tracks for important railways are required rank II; and 3. Other non-critical soil structures are required rank III.

Level 1 design seismic load is used in the pseudo-static seismic stability analysis, which is assigned to be a horizontal seismic coefficient at the ground surface $k_{\mathrm{h}}$ equal to 0.2 . This design seism load is equivalent to the conventional one that had been used before the revision of the code (i.e., before the 1995 Great Kobe Earthquake). It is assumed that the acceleration is not amplified inside soil structures. Level 2 design seismic load was newly introduced, which is equivalent to severe seismic loads experienced during the 1995 Great Kobe Earthquake. This is assigned in terms of standard time histories of horizontal acceleration at the ground surface and is used to evaluate the residual deformation of soil structure by the modified Newmark sliding block analysis. Depending on the natural period $T_{\mathrm{g}}$ of the ground at a given site, different wave forms and amplitudes are assigned. The assigned peak accelerations $a_{\text {max }}$ are very high, in a range from 500 to 920 gals $\left(\mathrm{cm} / \mathrm{s}^{2}\right)$.

Secondly, it is among the very important lessons learned from failure and collapse of a great number of embankments and conventional-type RWs by heavy rains, floods, and severe earthquakes that good compaction of and good drainage for the backfill are 
Table 1 Three performance ranks for two design seismic load levels

Design seismic load level Level 1: conventional design
EQ load ${ }^{\mathrm{a}}$

Level 2: severe seismic loads as experienced during the 1995 Kobe $\mathrm{EQ}^{\mathrm{b}}$

Required performance rank

$\begin{array}{ccc}\begin{array}{c}\text { Very important soil structures: } \\ \text { e.g., high speed trains (rank I) }\end{array} & \begin{array}{c}\text { Limited deformation: expected } \\ \text { functions can be maintained } \\ \text { without repair works }\end{array} & \begin{array}{c}\text { Allowed to exhibit deformation } \\ \text { as far as their functions can be } \\ \text { restored by quick repair works }\end{array} \\ \begin{array}{c}\text { Important soil structures: e.g., } \\ \text { urban trains (rank II) }\end{array} & \begin{array}{c}\text { Limited deformation: expected } \\ \text { functions can be maintained } \\ \text { without repair works }\end{array} & \begin{array}{c}\text { Should not exhibit devastating } \\ \text { deformation. The functions can } \\ \text { be restored by repair works }\end{array} \\ \begin{array}{c}\text { Other non-critical soil structures } \\ \text { (rank III) }\end{array} & \text { Should not collapse } & \text { Not specified }\end{array}$

\footnotetext{
${ }^{a}$ Anticipated to take at a given site several times during the design life time

${ }^{\mathrm{b}}$ The largest seismic load anticipated at a given site during the design life time
}

essential to prevent such failure and collapse. To facilitate good compaction of the backfill, with GRS RW having FHR facing (Fig. 1), the spacing between vertically adjacent geosynthetic layers is specified to be $30 \mathrm{~cm}$, while the standard compacted lift of soil layer is $15 \mathrm{~cm}$. Besides, it is allowed to use the $\phi_{\text {peak }}$ values listed in Table 2 in the design against level 2 seismic load only when good compaction is ensured. For example, for very important soil structures that are required to exhibit performance rank I against level 2 seismic load, both of the following criteria should be satisfied to use these $\phi_{\text {peak }}$ values: (1) all measured values of $D_{\mathrm{c}}$ (Standard Proctor) $\geq 92 \%$, and the average $\geq 95 \%$; and (2) all measured values of the coefficient of vertical subgrade reaction $\left(K_{30}\right)$ obtained by plate loading tests using a 30 -cm-diameter plate $\geq 70 \mathrm{MN} /$ $\mathrm{m}^{2}$, and the average $\geq 110 \mathrm{MN} / \mathrm{m}^{2}$. The standard design angles of internal friction, $\phi$ listed in Table 2 were determined conservatively based on results of a comprehensive series of drained triaxial compression tests on many backfill samples representative of the railway soil structures in Japan. Note that even higher angles of internal friction of the backfill can be used if they are confirmed by relevant investigations including laboratory stress-strain tests.

Good drainage is another key for high performance of soil structures. With the GRS RW having FHR facing (Fig. 1), gravel bags, or their equivalent, are placed at the shoulder of each soil layer to help better backfill compaction. They are also expected to

Table 2 Standard design values of density and angle of internal friction, $\phi$ for wall design

\begin{tabular}{lll}
\hline Soil type & $\phi_{\text {res }}(\mathrm{deg})$ & $\phi_{\text {peak }}(\mathrm{deg})$ \\
\hline 1. Well-graded gravelly soil & $40^{\circ}$ & $55^{\circ}$ \\
2. Well-graded sandy soil & $35^{\circ}$ & $50^{\circ}$ \\
3. Poorly graded sand (FC $<30 \%)$ & $30^{\circ}$ & $45^{\circ}$ \\
4. Soils with fines (FC $>30 \%)$ & $30^{\circ}$ & $40^{\circ}$ \\
\hline
\end{tabular}

Apparent cohesion due to suction is ignored (i.e., $c=0$ ). These $\phi_{\text {peak }}$ values can be used only when wellcompacted: (1) all measured values of $D_{\mathrm{c}}$ (standard Proctor) $\geq 92 \%$, and the average $\geq 95 \%$; and (2) plate loading test criteria are satisfied. Otherwise, $\varphi_{\text {res }}$ should be used 
function as a vertical drainage during service. The water percolating into the gravel bags from the backfill is drained to the outside of the wall through small pipes arranged for every 2 to $4 \mathrm{~m}^{2}$ in the facing. It is considered that, with good drainage, positive water pressure may not develop even during heavy rains. At the same time, with all soil types, the apparent cohesion, which is basically due to matrix suction, is ignored (i.e., $c=0$ ) in the design of walls under not only static but also seismic loading conditions. This is because the apparent cohesion may disappear in an uncontrolled manner with an increase in the moisture content, typically by heavy rainfall; therefore, it is not reliable. By the same concept, the saturated unit weight of soil is used in all cases.

Thirdly, the design is performed on the basis of the limit equilibrium stability analysis (i.e., static analysis and pseudo-static analysis as the first approximation of rigorous dynamic analysis). On the other hand, the earth pressure in the unreinforced backfill of full-scale RWs and tensile geosynthetic forces in full-scale GRS RWs that are measured under ordinary conditions are usually substantially lower than respective design values. This is because the design values are determined for critical and unusual conditions (i.e., heavy rains and severe earthquakes) while the measured values are significantly affected by matrix suction, which may disappear with an increase in the moisture content. Besides, the earth pressures and reinforcement forces measured under ordinary conditions do not include the effects of severe seismic loads. Furthermore, even under saturated conditions, the actually operated drained shear strength of wellcompacted backfill is usually significantly higher than the conservatively determined design values. In addition, the passive earth pressure at the foundation of the facing, which has significant effects on the tensile forces in the reinforcement, is ignored in design. For these reasons, these measured values are not referred to in the wall design for railways, as well as for roads.

Fourthly, the seismic performance of a given soil structure against level 1 design seismic load is evaluated based on the global factor of safety obtained by pseudo-static limit equilibrium stability analysis. On the other hand, the performance against level 2 design seismic load of unreinforced embankment is evaluated based on residual displacement obtained by the modified Newmark sliding block theory. The basis for this analysis is also pseudo-static limit equilibrium stability analysis. With wellcompacted backfill, it is conservatively assumed that, after having reached the peak value $\phi_{\text {peak }}$, the angle of internal friction $\phi$ suddenly drops to the residual angle $\phi_{\text {residual }}$. With actual compacted backfill, the strength fully drops only after some shear deformation increment that is essentially proportional to the particle size takes place $[13,21]$.

The residual deformation of RWs, including GRS RWs, is obtained by the modified Newmark theory based on the seismic earth pressure obtained by the modified Mononobe-Okabe seismic earth pressure theory. The original Mononobe-Okabe theory evaluates the seismic earth pressure in the framework of Coulomb's theory, using a single linear failure plane in the case of unreinforced backfill. It is assumed that, in the homogeneous backfill, the peak friction angle $\phi$ is kept constant everywhere and every time (i.e., the isotropic perfectly plastic assumption). Therefore, the failure plane moves for every change in the input seismic load. For example, when the input seismic load continuously increases, the failure plane continuously becomes deeper (i.e., in Fig. 10a, the angle $\alpha$ continuously decreases). In actuality, however, with well-compacted backfill, the $\phi$ value drops from $\phi_{\text {peak }}$ toward $\phi_{\text {residual }}$ only inside a shear band (i.e., a failure plane), while $\phi$ remains equal to $\phi_{\text {peak }}$ in the outer, unfailing zones. Therefore, 
when the input seismic load becomes higher than a certain level at which the development of the first failure plane has started, this first failure plane develops further without forming the second, deeper failure plane until the input seismic load becomes large enough to develop the second failure plane. Therefore, during a given time history of seismic load, multiple failure planes may stepwise develop in the backfill. Taking into account this process, Koseki et al. [22] proposed the modified $M-O$ theory.

For a simple RW configuration with unreinforced backfill (Fig. 10a), Fig. 10b, c compares the size of the failure zone and the horizontal earth pressure coefficient $K_{\mathrm{A}}$ plotted against the horizontal seismic coefficient $k_{\mathrm{h}}$ obtained by the original M-O theory when $\phi$ is equal to either $\phi_{\text {residual }}=30^{\circ}$ or $\phi_{\text {peak }}=50^{\circ}$ and the modified $M$ - $O$ theories for these $\phi_{\text {residual }}$ and $\phi_{\text {peak }}$ values. In the current design based on the modified $M-O$ theory, it is conservatively assumed that $\phi$ suddenly drops from $\phi_{\text {peak }}$ to $\phi_{\text {residual }}$. The following trends may be seen from Fig. $10 \mathrm{~b}$, c. Firstly, the $K_{\mathrm{A}}$ value by the original theory using $\phi_{\text {residual }}$ (i.e., the usual conventional design for sand backfill) becomes extremely high when $k_{\mathrm{h}}$ becomes higher than a certain value (say 0.4). By this feature, the seismic design of RWs for level 2 seismic load becomes very difficult when based on the original theory using $\phi_{\text {residual }}$. On the other hand, the $K_{\mathrm{A}}$ value evaluated by the modified theory increases stepwise with a continuous increase in $k_{\mathrm{h}}$, while the $K_{\mathrm{A}}$ value is always smaller than the value by the original theory using $\phi_{\text {residual }}$ with the difference increasing as $k_{\mathrm{h}}$ increases. Secondly, with a continuous increase in $k_{\mathrm{h}}$, the failure zone by the modified theory becomes larger stepwise and is consistently smaller than both of those by the original theory using $\phi_{\text {peak }}$ and $\phi_{\text {residual }}$. This trend is consistent with the model shaking table tests $[19,20]$ and field observations (e.g., Fig. 7a; [1, 13]).

In the current design of GRS RWs with FHR facing in practice, the seismic stability analysis is performed based on the pseudo-static limit equilibrium stability analysis by the two-wedge (TW) method using both $\phi_{\text {peak }}$ and $\phi_{\text {residual }}$ [13]. This modified TW method is a direct extension of the modified $M-O$ theory. A possible increase in the tensile resistance of reinforcement associated with residual deformation of the wall is ignored as a conservative simplification.

In Fig. 11, the seismic active earth pressure for a GRS RW having relatively short reinforcement is evaluated by the TW method. In the same way as the modified M-O method for unreinforced backfill, the first failure planes comprising two wedges develop in the reinforced backfill when $k_{\mathrm{h}}$ becomes a certain value, which is assumed to be equal to 0.2 in this example case. As $k_{\mathrm{h}}$ increases, the $\phi$ value inside the first failure planes drop from $\phi_{\text {peak }}$ to $\phi_{\text {residual, while this first failure planes continue }}$ developing until the second failure planes develop. For the wall configurations, Fig. 11a, c compares the coefficient $\left(\mathrm{K}_{\mathrm{A}}\right)_{\text {seismic }}$ for the seismic active earth pressure acting on the back face of the FHR facing when the safety factor for either over-turning or sliding failure becomes the minimum evaluated by the conventional TW methods using either $\phi_{\text {peak }}=45^{\circ}$ or $\phi_{\text {residual }}=30^{\circ}$ and the modified TW method using both of these $\phi$ values. It may be seen from Fig. 11c that the modified TW method yields reasonable values of earth pressure that are between those obtained by the conventional TW methods using either $\phi_{\text {peak }}$ or $\phi_{\text {residual }}$. Figure 11a compares the failure planes when $k_{\mathrm{h}}=0.5$ evaluated by these different TW methods (Fig. 11b). They are also compared with those for unreinforced backfill by the original $M O$ method using either $\phi_{\text {peak }}$ or $\phi_{\text {residual. }}$ The failure planes in the reinforced backfill evaluated by the conventional TW 
Fig. 10 a Considered simple wall configurations, and comparisons between the original and modified Mononobe-Okabe theories; b horizontal seismic earth pressure coefficient; and $\mathbf{c}$ the size of failure zone [22] a

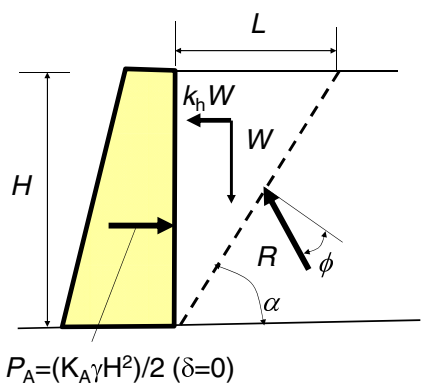

b

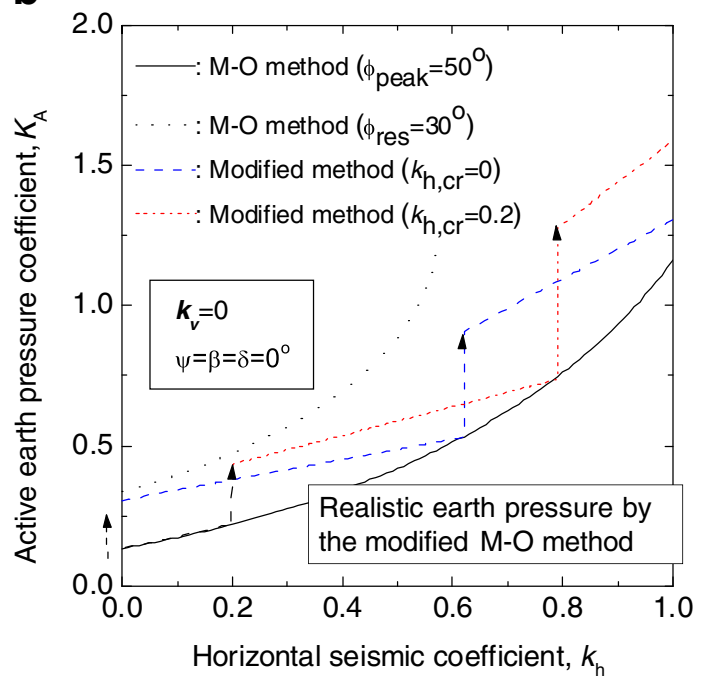

C

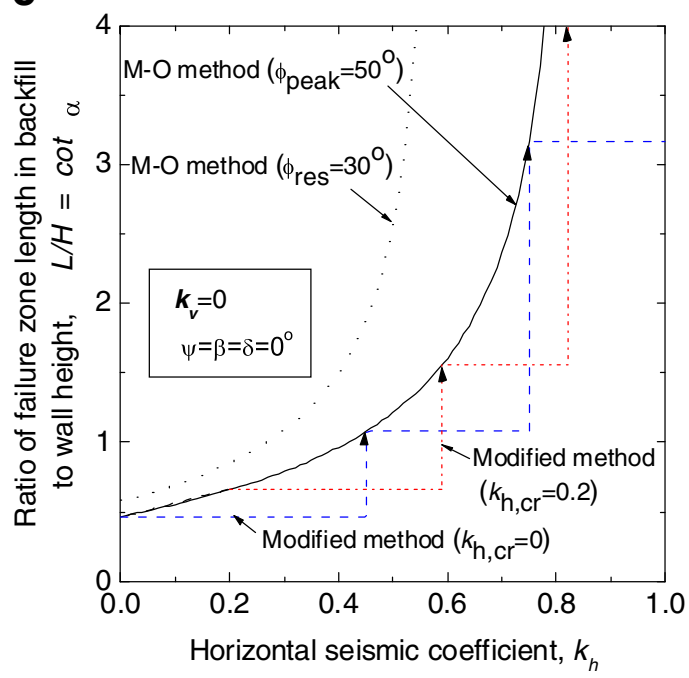


method using either $\phi_{\text {peak }}$ or $\phi_{\text {residual }}$ are similar to those for the unreinforced backfill evaluated by the original $M O$ method using either $\phi_{\text {peak }}$ or $\phi_{\text {residual }}$ On the other hand, the failure planes evaluated by the modified $M O$ method are much smaller, being largely modified by the effects of reinforcement, despite that the reinforcement is rather short. Figure 11d compares the size of the failure zone, where $L^{*}$ is the total length of the two wedges at the backfill crest. The failure zone evaluated by the modified TW method is considerably smaller, but more realistic, than those obtained by the conventional TW method.

For a typical GRS RW wall configuration depicted in Fig. 12a, b, it compares the overall safety factors for failure by sliding and overturning obtained by the TW method using $\phi_{\text {peak }}$ and $\phi_{\text {residual }}$ with those by the TW method using either $\phi_{\text {peak }}$ or $\phi_{\text {residual }}$. The response amplification inside the RW is ignored. In this analysis, it is assumed that the first failures develop in the backfill when $k_{\mathrm{h}}=0.28$. The critical failure planes obtained by the modified TW method under this condition are depicted in Fig. 12a. It may be seen that the safety factor by the modified TW method (using $\phi_{\text {peak }}$ and $\phi_{\text {residual }}$ ) is always in between the values by the TW method using $\phi_{\text {residual }}$ (i.e., the conventional design) and the TW method using $\phi_{\text {peak }}$.

Based on such results of analysis as shown above, (1) horizontal sliding displacement, (2) overturning displacement, and (3) shear deformation of the reinforced backfill are evaluated by the modified Newmark method. The allowable residual deformation of a given soil structure is specified by the owner of the concerned soil structure based on the criteria shown in Table 1. For example, for performance rank III, the ballasted track may allow a maximum residual settlement of $50 \mathrm{~cm}$.

Fifthly, in the same way as other ordinary design procedures for GRS structures, the design rupture strength for long-term static loading conditions $\left(T_{\mathrm{d}}\right)_{\text {static }}$ of geosynthetic reinforcement is obtained by applying a set of reduction factors to "tensile rupture strength obtained by fast loading test of new product $T_{\text {ult }}$ (Fig. 13). These reduction factors account for (1) installation damage, (2) long-term biochemical degradation, (3) the possibility of creep rupture, and (4) overall safety factor, $\mathrm{F}_{\mathrm{s}}$. With respect to the creep reduction factor, it is specified in the related Japanese Railway Design Code that the $T_{\mathrm{d}}$ value (i.e., the $T_{\text {ult }}$ value after applying reduction factors (1), (2) and (3) but before reducing by using the overall safety factor, $\left.\left(F_{\mathrm{s}}\right)_{\text {static }}\right)$ is equal to the maximum load value below which the creep failure does not take place at the end of 50 years. It is postulated that the above condition is satisfied if the strain rate after $500 \mathrm{~h}$ becomes smaller than $3.5 \times 10^{-5} / \mathrm{h}$ in all three creep loading tests on a given geosynthetic reinforcement type.

In the Japanese Railway Design Codes, the design seismic rupture strength $\left(T_{\mathrm{d}}\right)_{\text {seismic }}$ is obtained not taking into account the creep reduction factor that is determined to avoid creep rupture under static loading conditions for the following three reasons:

1. The design rupture strength $\left(T_{\mathrm{d}}\right)_{\text {static }}$ (before applying $\left.\left(F_{\mathrm{s}}\right)_{\text {static }}\right)$ required for a given GRS RW is determined by limit equilibrium stability analysis using several conservative assumptions (i.e., using conservative design values of $\phi$ while ignoring apparent cohesion and toe resistance). The creep reduction factor is determined by assuming that the tensile load is kept to this design static strength during the lifetime of the structure. As explained earlier, the actual tensile load ( $L_{\mathrm{a}}$ in Fig. 13) activated under ordinary non-critical conditions, which occupies most of the design lifetime, is considerably lower than this value of $\left(T_{\mathrm{d}}\right)_{\text {static. }}$. 
Fig. 11 Comparison between the conventional method and the modified TW method assuming that the first active failure develops when $k_{\mathrm{h}}=0.2$ : a wall configurations with failure planes; $\mathbf{b} \phi$ values used in the analysis (the dimensions are not to scale); $\mathbf{c}$ active earth pressure coefficient $K_{\mathrm{A}}$, and the ratio of failure zone length at the crest to the wall height [13]

2. As illustrated in Fig. 13, it is conservatively assumed that the creep process starts after the geosynthetic reinforcement has fully deteriorated (i.e., the resistance against creep has decreased) by long-term biochemical effects by the end of the lifetime, although, in actuality, the creep process starts contemporarily with material degradation [23].

3. Figure 14 shows typical tensile loading test results. In one of the three tests, sustained loading (SL) was applied for 30 days during otherwise monotonic loading (ML) at a constant strain rate. Upon the restart of ML at a constant strain rate after $\mathrm{SL}$, the load-strain relation soon rejoins the one from the continuous ML loading tests (not including a sustained loading stage). The rupture strength in these three tests is a rather unique function of the strain rate at rupture and essentially the same whether SL is applied at an intermediate stage. This result indicates that, unless the material property degrades with time by chemical and/or biological effects, the original strength for a given strain rate of a given geosynthetic reinforcement is maintained until late in its service life. That is, when subjected to seismic loads after some long service period under constant load conditions, the original strength at a fast strain rate can be fully activated [2, 24-27].

Lastly, as a whole, it is highly recommended to employ GRS structures in place of conventional-type embankments, RWs, and bridge abutments with unreinforced backfill when and where relevant and feasible. In fact, it is extremely difficult to costeffectively design conventional-type soil structures against level 2 seismic load. On the other hand, when the backfill is well-compacted and its effect on the design shear strength of backfill is taken into account (as described above), GRS structures become a cost-effectively solution and this feature can be indicated in design.

\section{Reconstruction of RWs and Embankments Collapsed by Earthquakes}

Numerous embankments and conventional-type RWs collapsed by earthquakes in the past. On the other hand, high performance of a GRS RW having stage-constructed FHR facing during the 1995 Great Kobe Earthquake validated its high-seismic stability (Fig. 8). Many gently sloped embankments and conventional-type RWs that collapsed by that and subsequent earthquakes were reconstructed to GRS RWs of this type [1, 10-13, 29]. Based on a high performance of the GRS RW at Tanata and the others during the 1995 Great Kobe Earthquake, as well as many previous successful case histories as described in this paper, a number of the conventional RWs that failed during the 1995 Great Kobe Earthquake were reconstructed to GRS RWs having a staged-constructed FHR facing. Figure 15 shows the one typical of the above. The seismic stability of the RWs that damaged, failed, and survived during the 1995 Kobe Earthquake was reported by Tatsuoka et al. [1, 13, 30].

Three railway embankments supported by gravity-type RWs on slope collapsed during the 2004 Niigata-ken Chuetsu Earthquake and they were reconstructed to GRS RWs of 
a

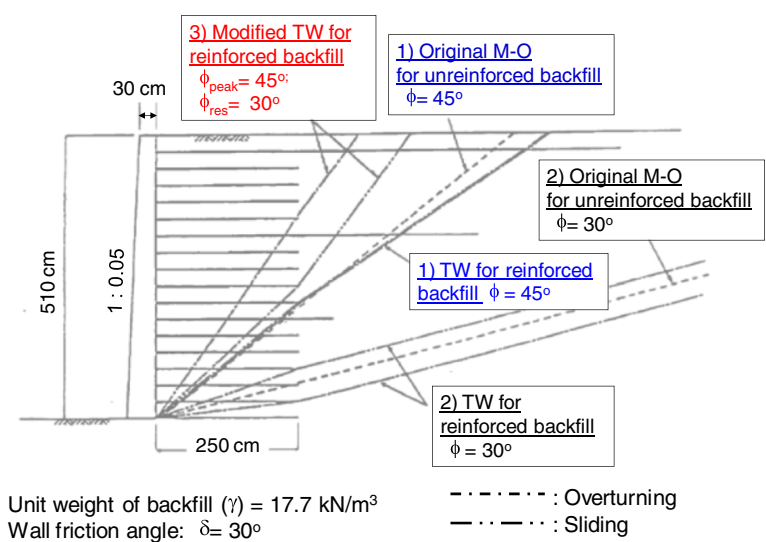

b

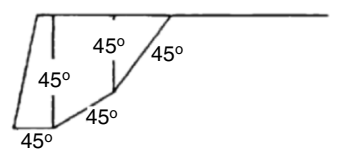

1) TW for reinforced backfill: always $\phi=$ $45^{\circ}$ at any point

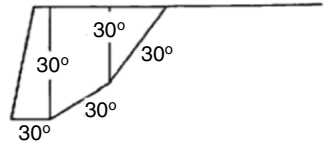

2) TW for reinforced backfill: always $\phi=30^{\circ}$ at any point

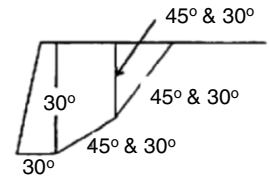

3) Modified TW for reinforced backfill: $\phi=\phi_{\text {peak }}\left(=45^{\circ}\right)$, then $\phi_{\text {res }}\left(=30^{\circ}\right)$

C

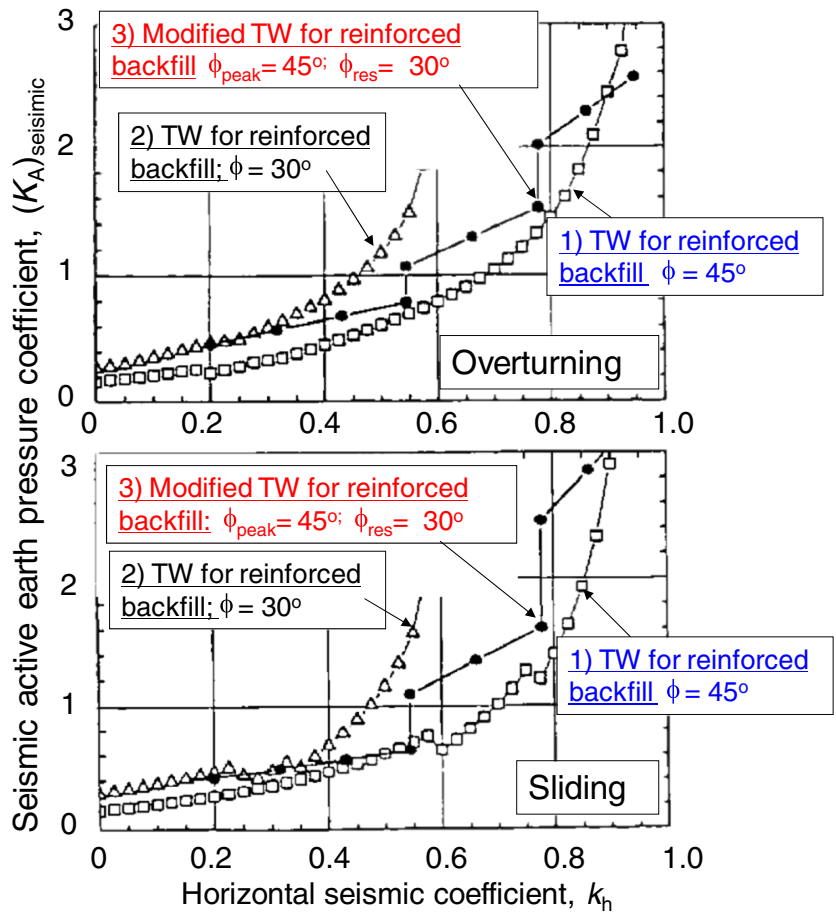




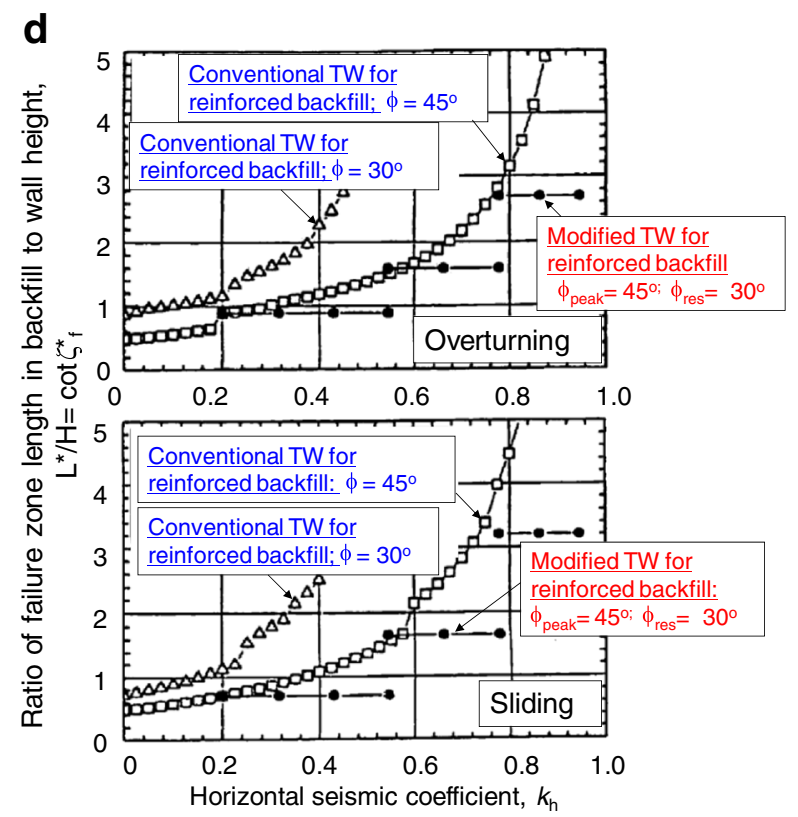

Fig. 11 (continued)

this type (Fig. 16). This technology was adopted due to not only much lower construction cost and much higher stability (in particular for these soil structures on steep slopes) but also much faster construction resulting from a significant reduction of earthwork when compared to the original gently sloped embankment with a gravity-type RW.

During the 2011 Great East Japan Earthquake, a number of GRS RWs of this type that had been designed based on the revised seismic design code described above and constructed in the affected areas of this earthquake performed very well (Fig. 9). In comparison, a great number of old embankments and RWs that were not designed and constructed following the current seismic design standard collapsed. Several conventional-type RWs and embankments that collapsed were reconstructed to GRS RWs of this type. Figure 17 shows a typical case. A very fast construction was one of the important advantages of this technology also in this case. In particular, the railway was re-opened at a restricted speed before constructing a FHR facing (Fig. 17b). Figure 18 shows one of the three embankments that collapsed during an earthquake induced 1 day after the 2011 Great East Japan Earthquake and reconstructed to GRS RWs of this type. It is now the standard practice to reconstruct conventional-type RWs and embankments for railways that collapsed by earthquakes to GRS RWs with FHR facing.

\section{GRS Structure for Bridge}

GRS Bridge Abutment

Large bumps may develop immediately behind a bridge abutment by depression of the unreinforced backfill and displacements of the wing RWs and the abutment during a 
Fig. 12 a GRS RW with FHR facing and critical failure planes by modified TW method, and $\mathbf{b}$ results of stability analysis: the tensile rupture strength of reinforcement $T_{\mathrm{d}}=30 \mathrm{kN} / \mathrm{m}$, and the friction angle at the reinforcement/backfill interface $\left(\phi_{\mathrm{B}}\right)$ and the back and bottom of facing $\left(\delta_{\mathrm{w}}\right)=\phi_{\text {residual }}$ of the backfill [18] a

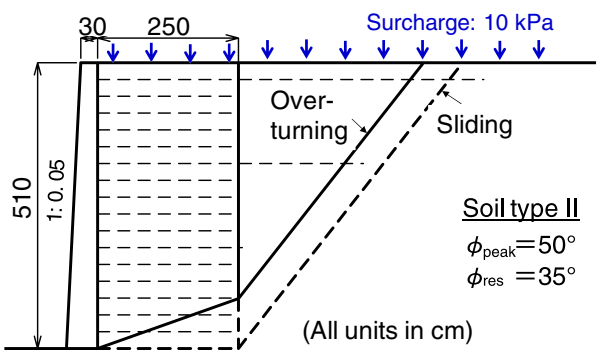

b

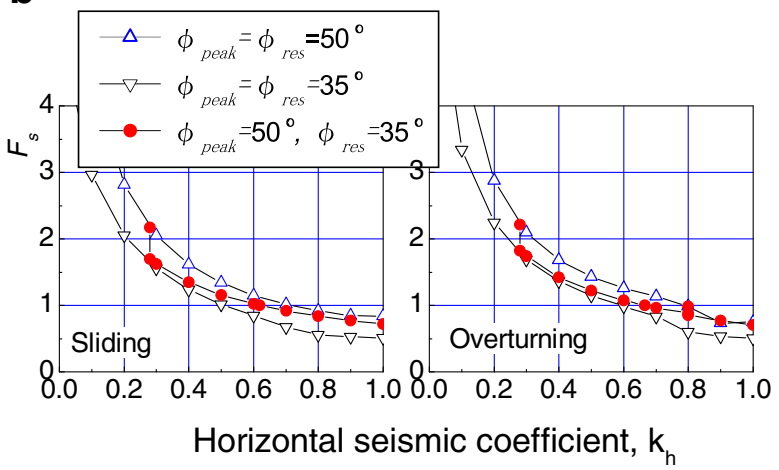

long period of service and by severe earthquakes. This is one of the most serious problems with conventional-type bridge abutments. To alleviate this problem, an approach block comprising compacted well-graded gravelly soil was introduced in the 1967 Design Standard for Railway Soil Structures. However, it was revealed that this measure is not effective. Subsequently, the authors and their colleagues developed

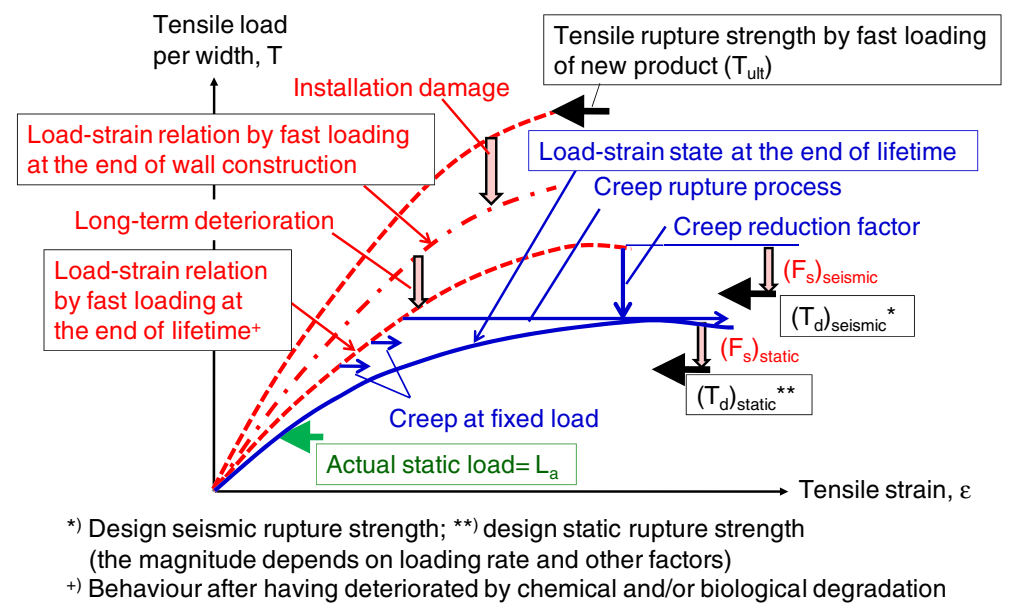

Fig. 13 Procedure to obtain the design rupture strengths $\left(T_{\mathrm{d}}\right)_{\text {static }}$ and $\left(T_{\mathrm{d}}\right)_{\text {seismic }}$ of geosynthetic reinforcement under long-term static and seismic loading conditions, compared with actual long-term static load $L_{\mathrm{a}}$ 


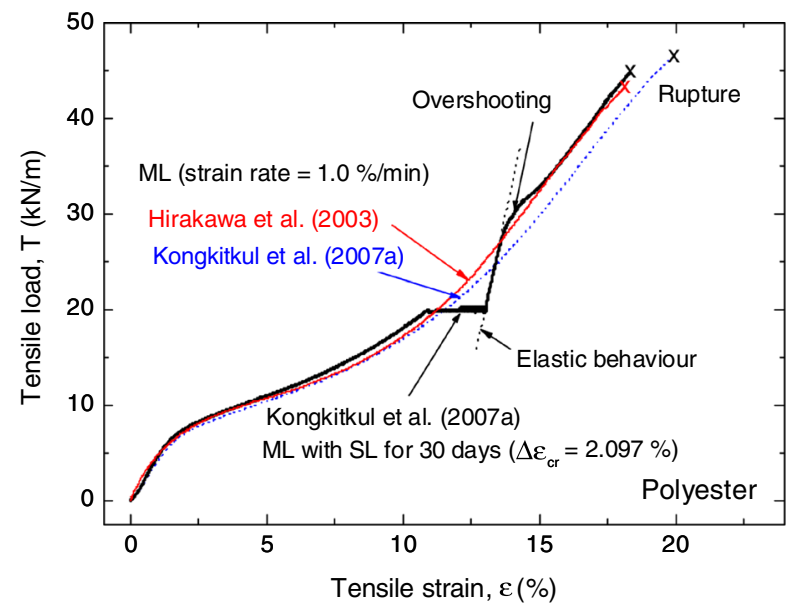

Fig. 14 Comparison of tensile load-strain relations from three monotonic loading tests with and without creep loading for 30 days at an intermediate load level, a PET geogrid [27, 28]

a new type bridge abutment (Fig. 19) [3, 4]. One end of a bridge girder is placed on the top of the FHR facing of a GRS RW via a fixed (i.e., hinged) bearing while the other end is placed on the top of a pier via a movable (i.e., roller) bearing: or both ends are placed on the top of the FHR facings of a pair of GRS RWs via a set of bearing (hinged and roller). To ensure high performance of bridges, in particular when constructed for high-speed trains, the backfill immediately behind the facing is well-compacted lightly cement-mixed well-graded gravelly soil that is reinforced with geogrid layers connected to the facing. The mixing proportion, field compaction control and the strength and deformation characteristics of cement-mixed soil currently used in the present practice are described in details in Tatsuoka et al. [4]. Yet, the gravel bags immediately behind the facing are filled with un-cemented gravelly soil so as to function as a drainage layer and a buffer that can absorb potential relative lateral displacements between the facing and the cement-mixed backfill caused by annual thermal deformation of the girder and seismic loads. The first advantage of the GRS bridge abutment described above is a much higher seismic stability with a minimum bump even against very severe seismic loads. Besides, this new type bridge abutment is much more cost-effective than the conventional type bridge abutment because the $\mathrm{RC}$ facing is much more slender and usually a pile foundation is not used. Without including a cost reduction with the foundation structure and long-term maintenance, the construction cost decreases typically by about $20 \%$ when compared with the conventional-type bridge abutment.

The first GRS bridge abutment of this type was constructed during a period of 20022003 at Takada for Kyushu Shinkansen [3, 4]. By performing full-scale vertical and lateral loading tests of the FHR facing, it was confirmed that the connection strength between the FHR facing and the geogrid-reinforced backfill is sufficiently high. For Hokkaido Shinkansen, in total 29 GRS bridge abutments of this type were constructed while no conventional-type bridge abutment was constructed. The tallest GRS bridge abutment is $13.4 \mathrm{~m}$ high (Fig. 20). Until today, in total about 50 GRS abutments of this type have been constructed for railways. 
a

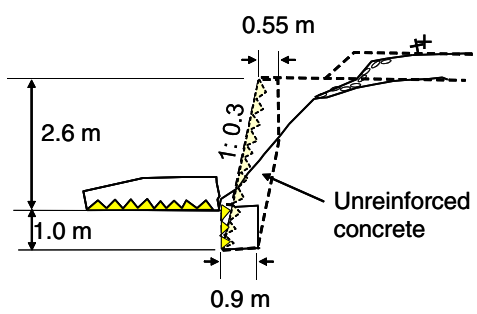

b

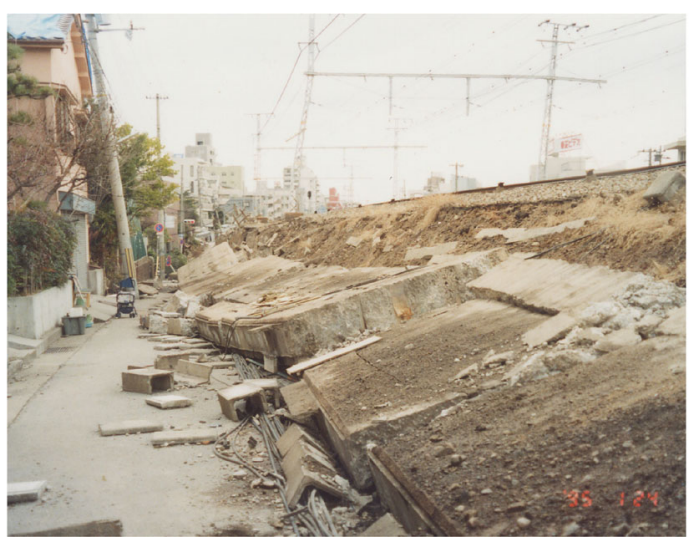

C

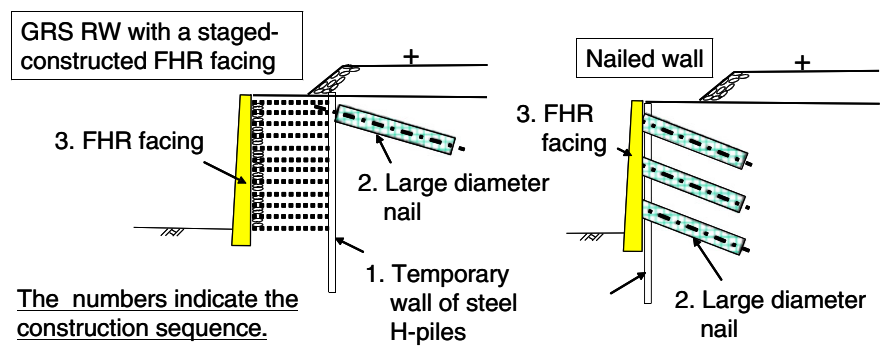

d

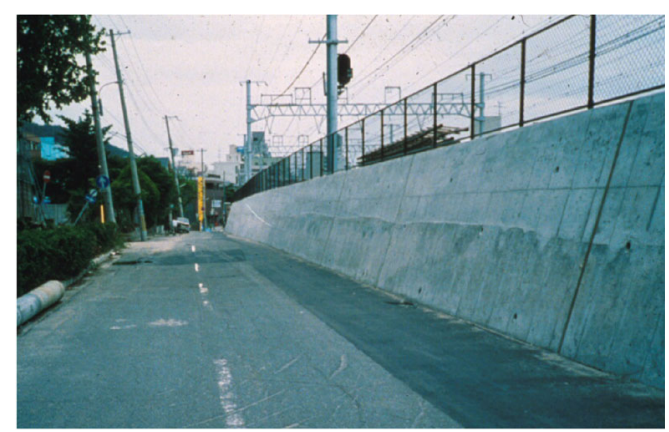

Fig. 15 Leaning-type RW of unreinforced concrete without a pile foundation between Setsu-motoyama and Sumiyoshi stations that collapsed during the 1995 Kobe Earthquake (Tatsuoka et al. [1, 30, 31]): a cross section and $\mathbf{b}$ a view of the collapsed wall; and $\mathbf{c}$ cross section and $\mathbf{d}$ a view after reconstruction 
Fig. 16 One of the railway embankments that collapsed during the 2004 Niigata-ken Chuetsu Earthquake and its reconstruction to a GRW RW having FHR facing: a cross sections before and after collapse compared with the one after reconstruction; $\mathbf{b}$ a view during construction; and $\mathbf{c}$ the first train on the wall [32]

\section{GRS Integral Bridge}

The use of bearings (movable or fixed or both) to support a girder is the remaining most serious problem with the GRS bridge abutment (Fig. 19). To alleviate this problem, the GRS integral bridge, illustrated in Fig. 21, was developed based on a series of model shaking table tests ([5-7], [8,9]; [33]) and the construction of a full-scale model (Fig. 22a, b; [34]) and loading tests performed 3 years after its construction (Fig. 22c; [35]). The stability of the full-scale model of GRS integral bridge was confirmed by applying design thermal deformation of the girder and level 2 design seismic load to the girder of the model. The current seismic design method of GRS integral bridge is described in Yazaki et al. [36].

In the same way as the GRS bridge abutment (Fig. 19), the GRS integral bridge (Fig. 21) exhibits negligible settlement in the backfill immediately behind the facing and negligible structural damage to the facing by lateral cyclic displacements of the facing caused by seasonal thermal expansion and contraction of the girder [7]. The only but significant difference of the GRS integral bridge (Fig. 21) from the GRS bridge abutment (Fig. 19) is that, with the GRS integral bridge, both ends of a continuous girder are integrated to the top of the FHR facing of a pair of GRS RWs without using bearings. The first advantage of the GRS integral bridges over bridges comprising GRS bridge abutments is that the construction and maintenance of bearing becomes unnecessary. Secondly, the RC girder becomes much more slender due to a significant reduction (by a factor of about 0.5 ) of the moment resulting from flexural resistance at the connection between the girder and the facing. Thirdly, as demonstrated by various model tests and numerical analysis, the seismic stability increases significantly due to an increased structural integrality and a reduced weight of the girder. Fourthly, due to higher structural integrality and a smaller cross-section of the girder, the resistance against tsunami loads increases significantly.

The first GRS integral bridge was constructed as the over-road bridge at Kikonai for Hokkaido Shinkansen (Fig. 23). As this is the first full-scale GRS integral bridge and as this is for high-speed trains, its high stability was and will be confirmed by monitoring the behavior continuously from the start of construction until sometime after the start of service (scheduled to be April 2014) [16, 37]. The ambient temperature and strains in the steel reinforcement in the RC structures, strains in the geogrid, the displacements of the RC structures, and the backfill and earth pressures at representative places are being observed. It was confirmed that the structure is not over-stressed at all. Results of detailed analysis will be reported by the authors in the near future.

\section{GRS Box Culvert}

At three sites (B1, B2, and B3 in Fig. 3b), where Hokkaido Shinkansen crosses local roads, RC box culverts (i.e., underpass structures) integrated to the geogrid-reinforced backfill on both sides (called GRS box culverts) were constructed. Figure 24a shows 
a

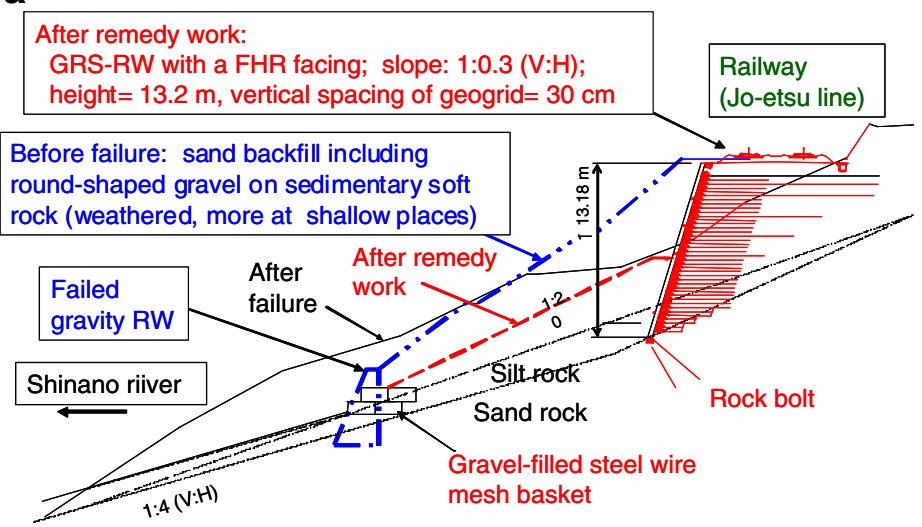

b

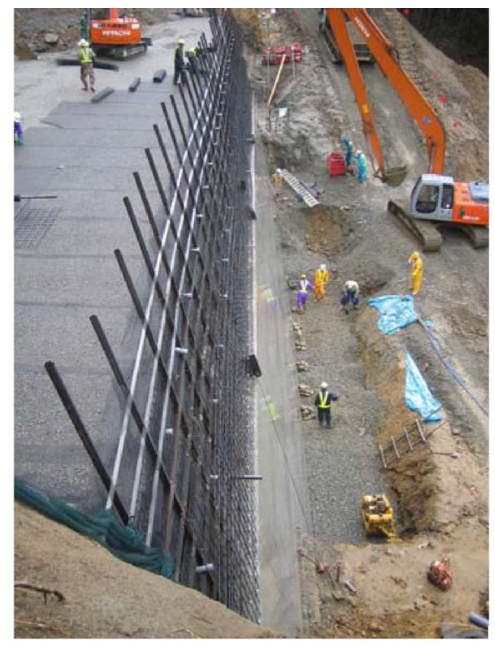

C

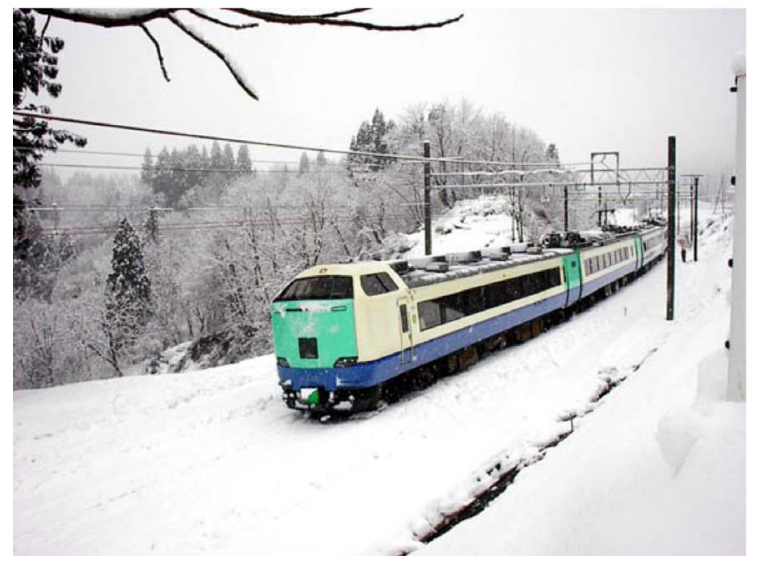


a

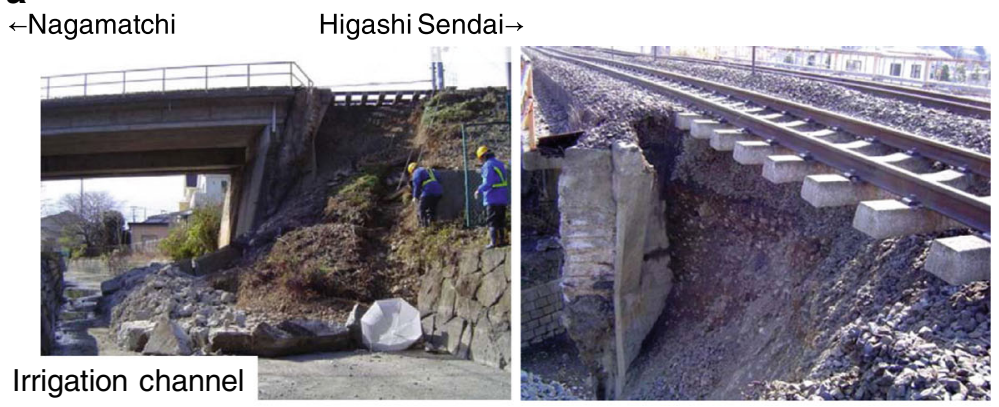

b

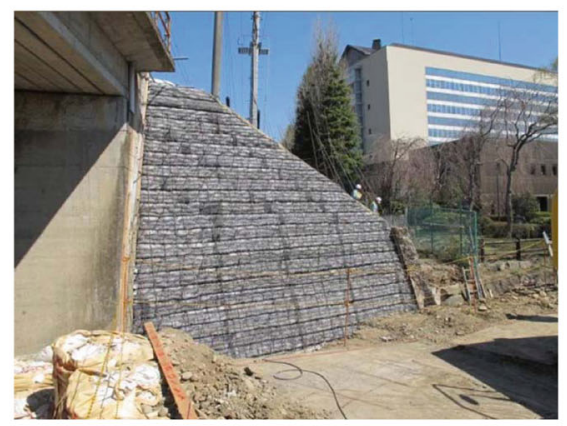

C

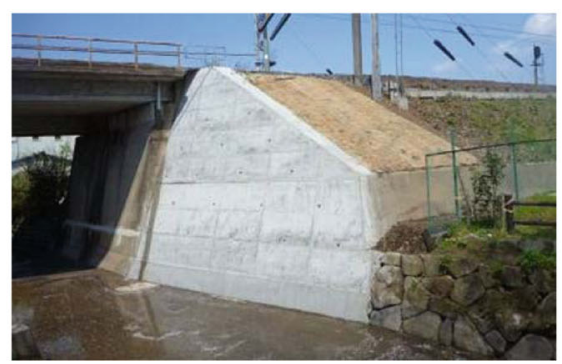

Fig. 17 a Collapse of a wing RW with a masonry facing of a bridge abutment (Nagamachi, Sendai for Tohoku Freight line); and $\mathbf{b}, \mathbf{c}$ its reconstruction to a GRS RW (by the courtesy of the East Japan Railway Co.)

the structure of those constructed at sites B2 and B3. At each of these sites, a RC box structure was firstly constructed as it was requested to re-open a local road as soon as possible. Then, GRS RWs comprising of well-compacted lightly cement-mixed wellgraded gravelly soil reinforced with geogrid layers were constructed at both sides leaving a narrow space as shown in Fig. 24b. Finally, concrete was cast-in-place into this space to integrate the RC box culvert to the GRS RWs. For a high integrality of the whole structure, horizontal anchor steel rods connected to the steel reinforcement framework of the RC box structure had been protruded into the space. When constructed on a thick soft soil deposit, it is more relevant to first construct approach fills on both sides, followed by the construction of a RC box structure after the ground settlement due to the 


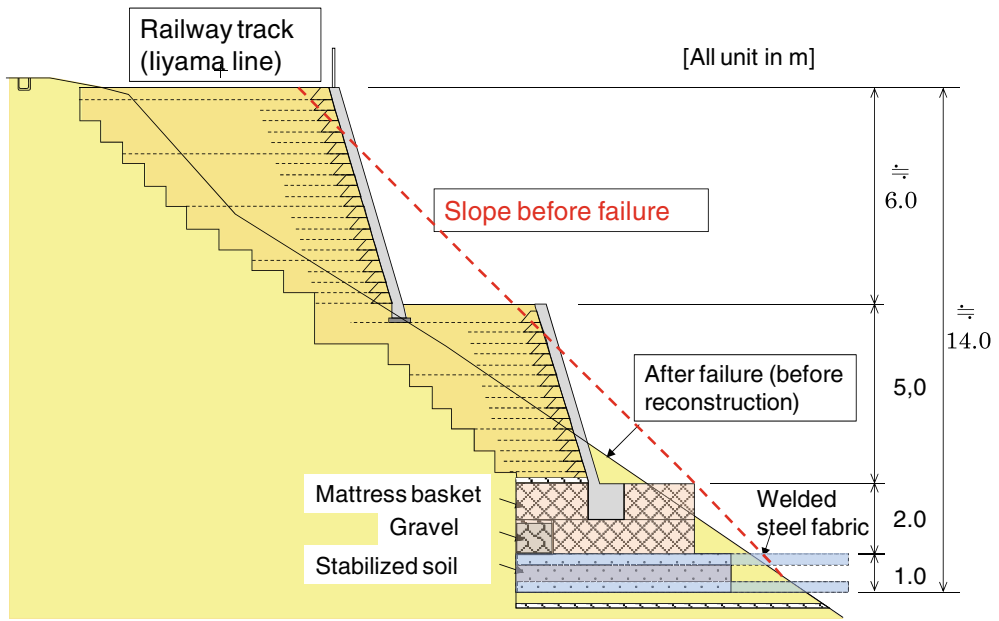

Fig. 18 One of the three embankments between Yokokura and Morinomiya stations, Iiyama Line, that collapsed during the Nagano-Niigata Border Earthquake and reconstructed to GRS RWs (by the courtesy of the East Japan Railway Co.)

weight of the approach fills has taken place sufficiently so that the RC box structure becomes free from negative effects of ground settlement.

A GRS box culvert has nearly the same superior features as a GRS integral bridge over a conventional type box culvert (in contact with unreinforced backfill on both sides). Yet,

Fig. 19 a GRS bridge abutment and $\mathbf{b}$ construction procedure

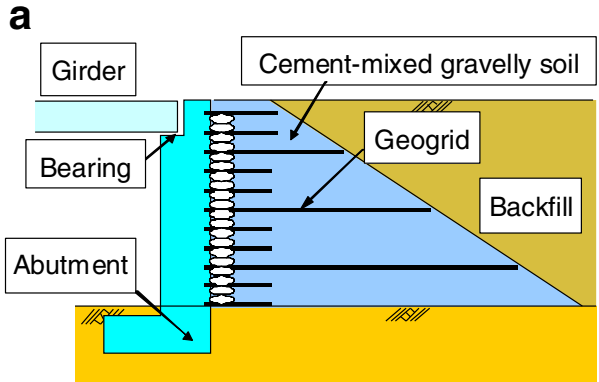

b
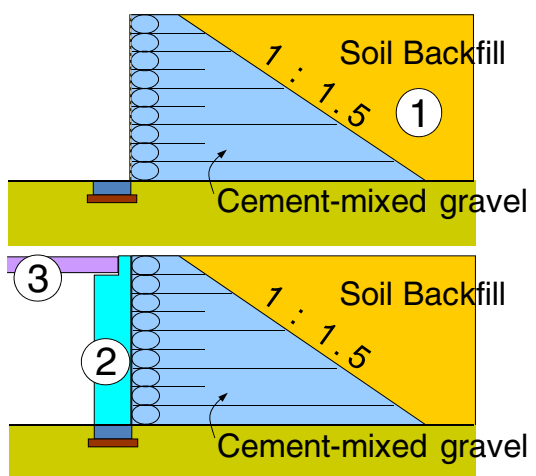
Fig. 20 GRS abutment at Mantaro for Hokkaido Shinkansen (A21 in Fig. 3b): views under construction: a from the front side and $\mathbf{b}$ from the backside, and completed $[15,16]$
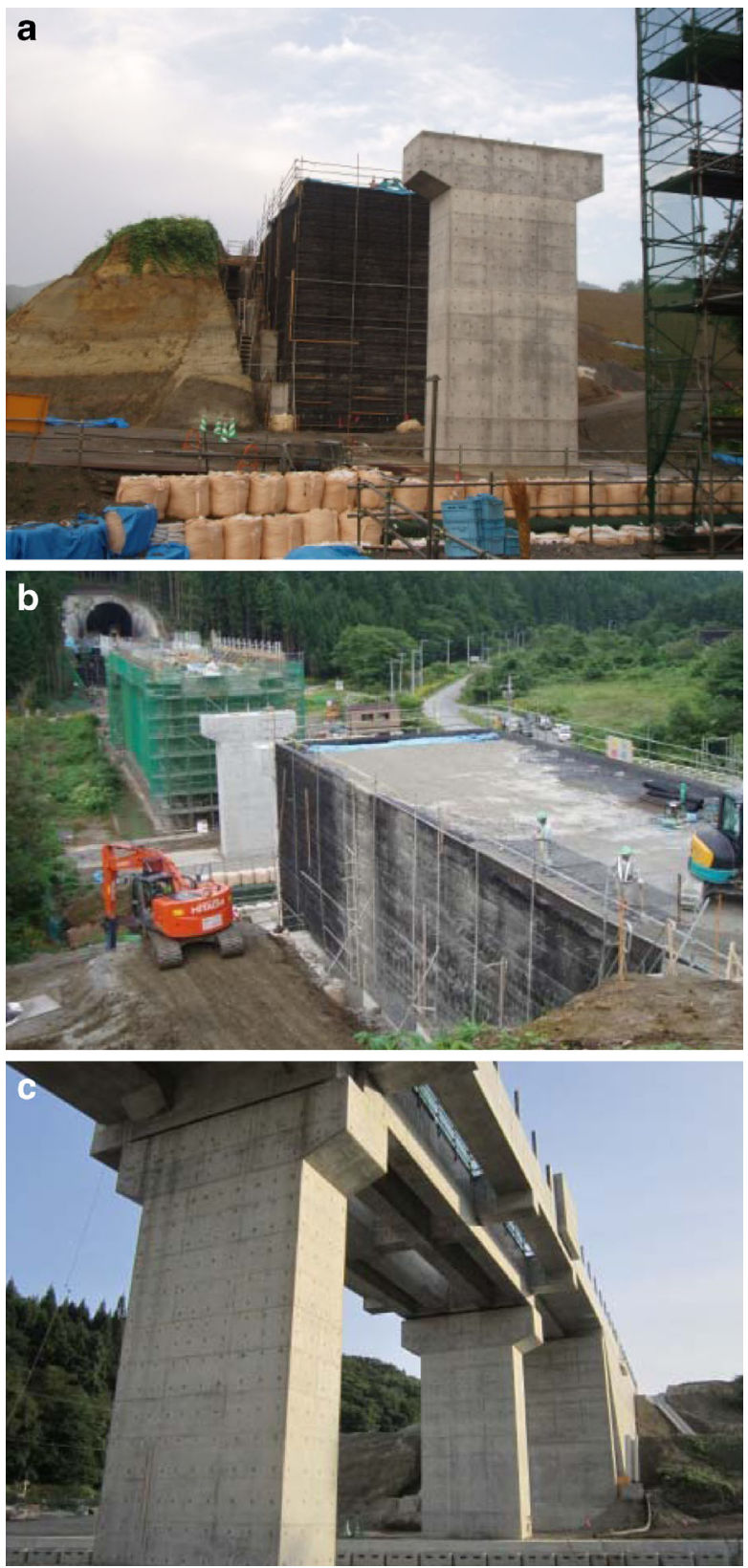

a GRS box culvert in the completed form is different from a GRS integral bridge only in that this has the bottom RC slab. Therefore, the contact pressure at the bottom face of the bottom RC slab of a GRS box culvert is much lower than the one at the facing bottom of a GRS integral bridge. In addition, the bottom RC slab functions as a strut for the facings. Therefore, the stability of a GRS box culvert is higher than a GRS integral bridge under 


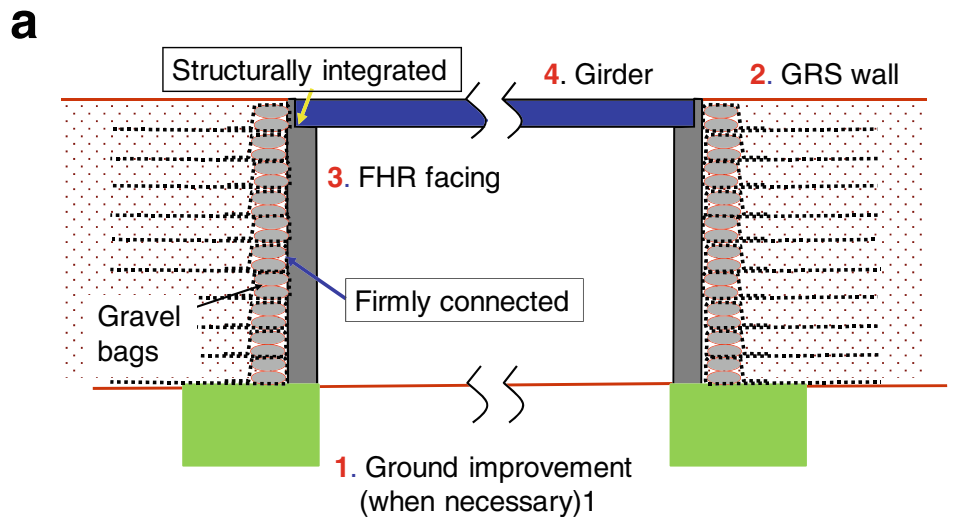

(when necessary) 1

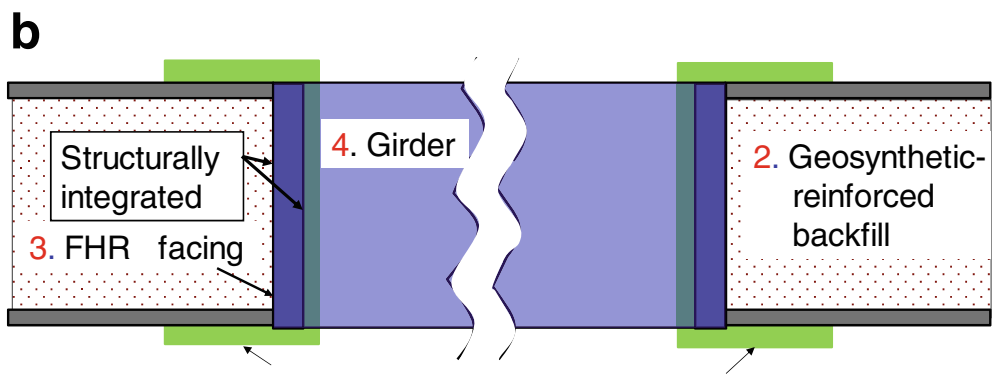

1. Ground improvement (when necessary)

Fig. 21 Construction sequence of GRS integral bridge: a elevation and $\mathbf{b}$ plan

otherwise the same conditions. On the other hand, for a longer span for which the bottom $\mathrm{RC}$ slab cannot be constructed, a GRS integral bridge becomes relevant.

\section{Floods and Tsunami}

\section{Some Latest Case Histories of Flood}

A great number of embankments for roads and railways retained by conventional-type cantilever RWs along rivers and seashores collapsed by floods and storm wave actions, usually triggered by over-turning failure of the RWs caused by scouring in the supporting ground (Fig. 25a; [29]). Upon the collapse of RW, the backfill is quickly and largely eroded, resulting in closing of railway or road. This type of collapse easily takes place, as the stability of a cantilever RW fully hinges on the bearing capacity at the bottom of the RW and the stability of the backfill fully hinges on the stability of the RW. On the other hand, GRS RWs with a FHR facing is much more stable against the scouring in the supporting ground (Fig. 25b). It is particularly important that the facing does not overturn easily and the backfill can survive unless the supporting ground is extremely scoured. As shown in Fig. 26a, a large-scale overturning collapse of gravity-type RW for a road (called Seisho bypass) took place for a length of about $1.5 \mathrm{~km}$ along a 
a

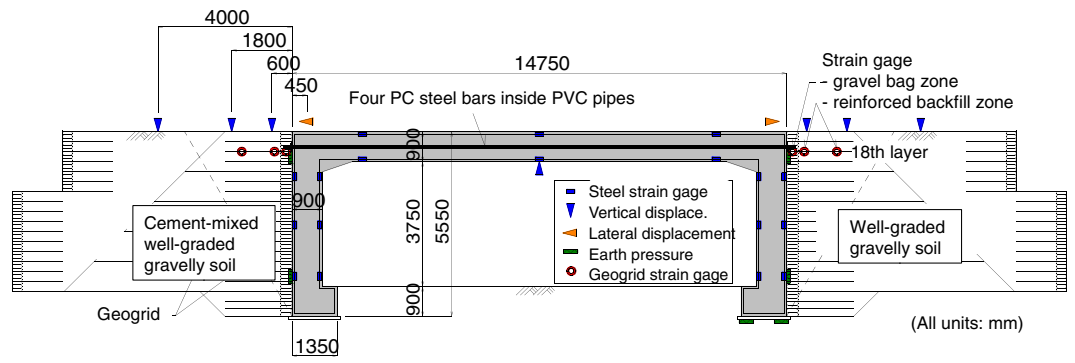

b
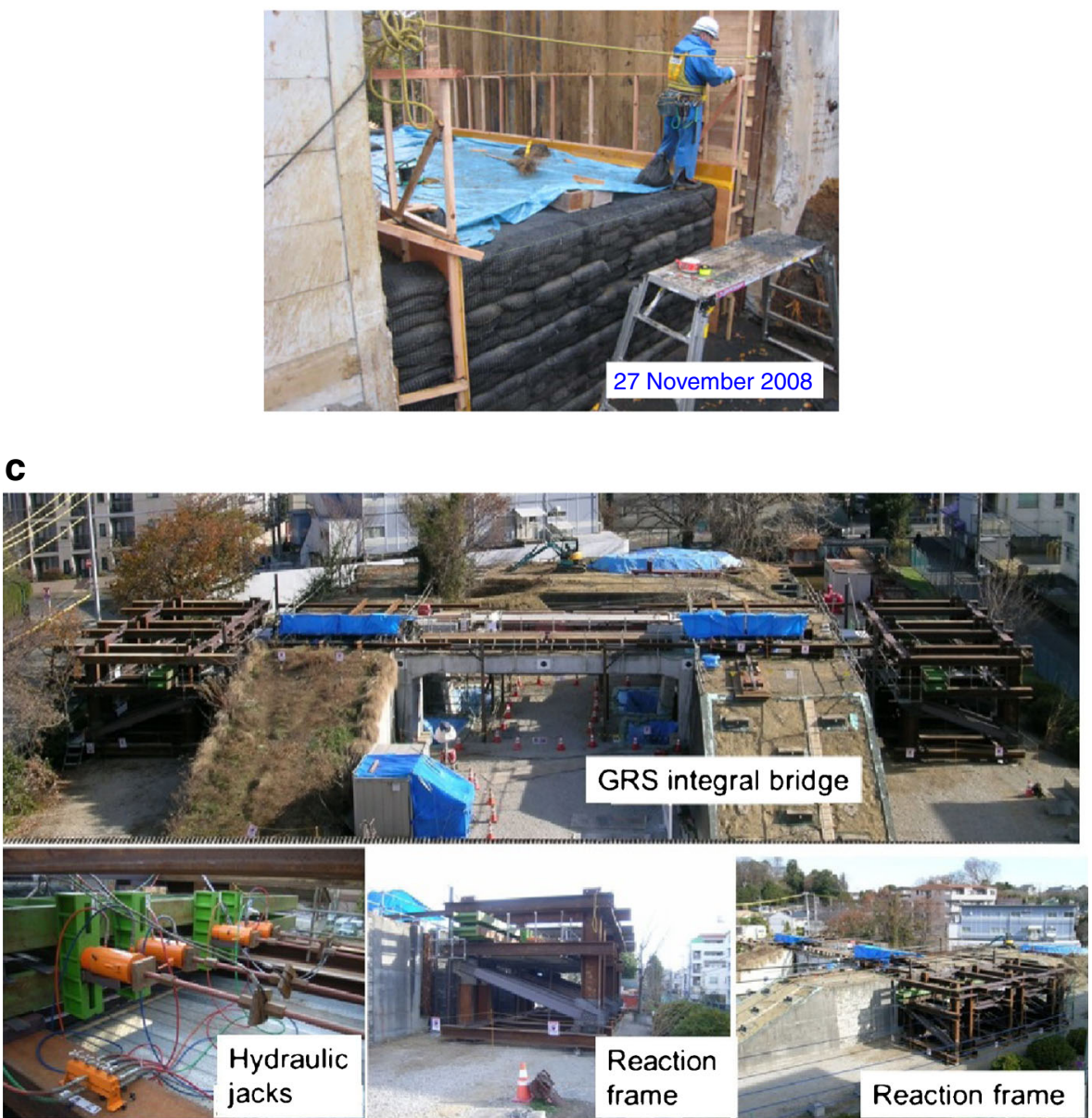

Fig. 22 A full-scale model of GRS integral bridge constructed at Railway Technical Research Institute: a overall structure; $\mathbf{b}$ the left-side abutment under construction; and $\mathbf{c}$ full-scale loading test performed in January 2012

seashore facing the Pacific Ocean near Tokyo. The collapse of the RW was triggered by scouring in the supporting ground by the mechanism illustrated in 


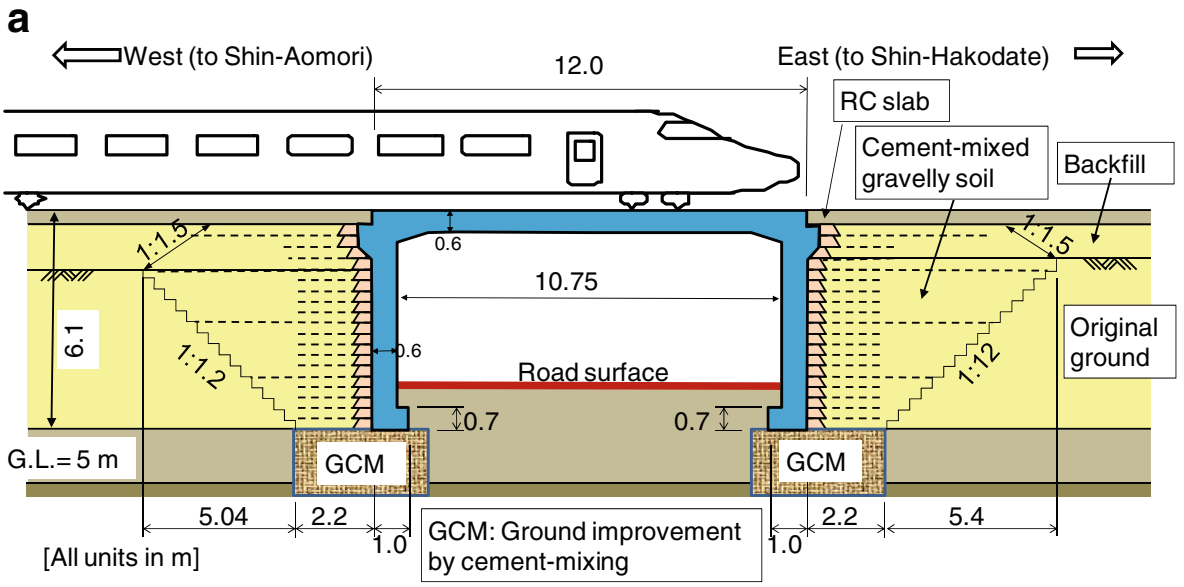

b

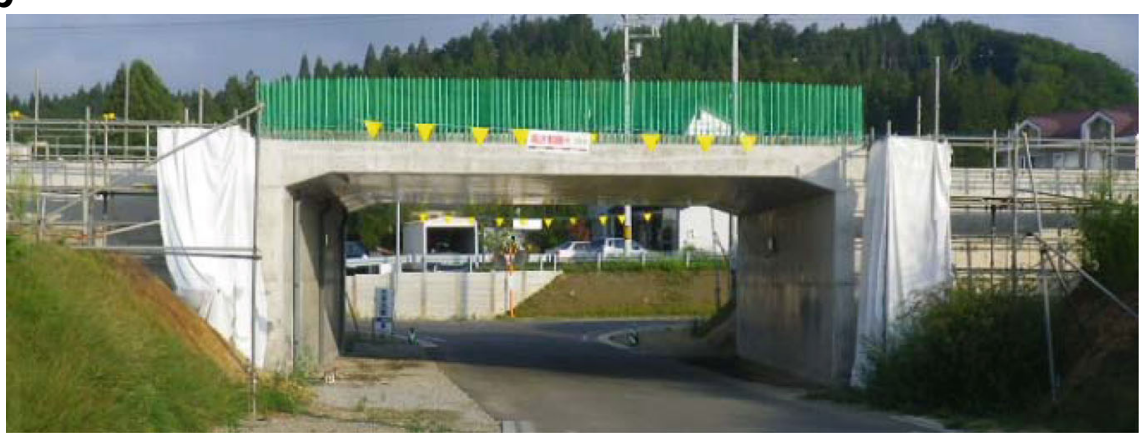

Fig. 23 GRS integral bridge at Kikonai, Hokkaido Shinkansen (at site I in Fig. 3b)

Fig. 25a due to strong ocean waves during a typhoon No. 9, 29 August 2007. The wall was reconstructed to a GRS RW with FHR facing (Fig. 26b, c).

Flood took place in many rivers by the Niigata-Fukusima Heavy Rainfall at the end of July 2011 [38]. In Tokamachi City (site A in Fig. 6a), the maximum rainfall intensity was $120 \mathrm{~mm} / \mathrm{h}$ and $294 \mathrm{~mm} /$ day. A high embankment retained by a masonry gravitytype RW at the lower part on the left bank of Agano River, Niigata Prefecture, for West Ban-Etsu Line of East Japan Railway (JR East) collapsed by the mechanism illustrated in Fig. 25a. The wall was reconstructed to an about 9.4-m-high- and 50-m-long GRS RW with a FHR facing. By this heavy rainfall, soil structures at more than 150 sites of Iiyama Line of JR East were seriously damaged. Among them, a masonry wing RW of the approach fill of Iruma River Bridge (site A in Fig. 6a) collapsed by the same mechanism (Fig. 27a, b). It was required to re-open the railway only in 10 days after the collapse. It takes much more days if the original masonry RW is reconstructed. On the other hand, it was feasible and less costly with a GRS RW (Fig. 27b). Figure 27c is a view during construction. The railway was re-opened with slowed-down running of trains before the construction of a FHR facing. Figure 27d shows the completed wall.

At site B (Fig. 6a) in the Mt. Aso area in Kyushu Island, a series of railway embankments located in narrow valleys between tunnels for Ho-Hi Line fully collapsed on 2 July 1990 by floods caused by rainfall (Fig. 28). Flood water was trapped in back 
a

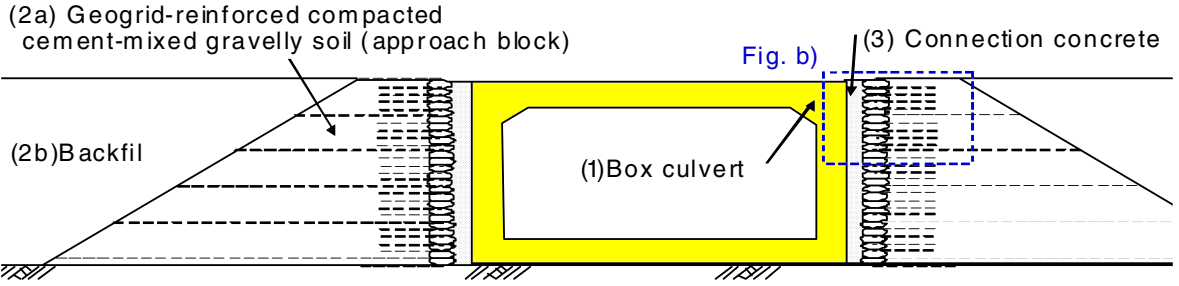

b

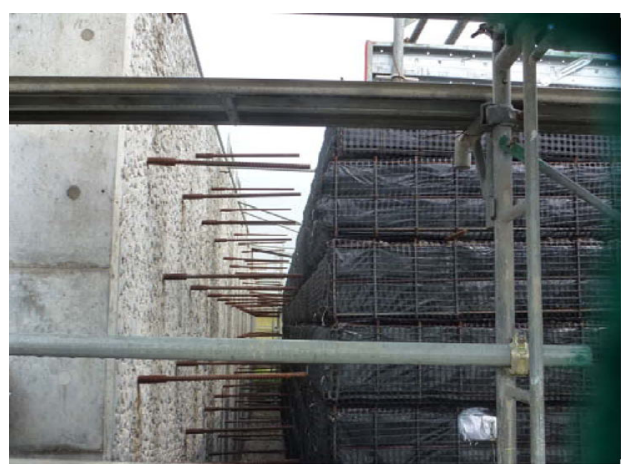

Fig. 24 GRS box culvert for Hokkaido Shinkansen: a general structure; the numbers denote the construction sequence (site B2 in Fig. 3b); and $\mathbf{b}$ a space between the RC box structure and the approach block before step (3) (site B1 in Fig. 3b) $[15,16]$

of the upstream slope of each embankment due to the clogging of a drain pipe crossing the embankment. The embankments collapsed by over-topping of the flood water. In the downstream, debris flows took place, as seen from Fig. 28a, and attacked several residential houses at the lower reach of the embankments. The six embankments were reconstructed to geosynthetic-reinforced embankments, as typically shown in Fig. 29, to reduce the amount of earthwork while keeping the stability of embankment to a sufficiently high level. To arrange a 3-m-diameter drain corrugate pipe crossing the embankment, a nearly vertical GRS RW with a FHR facing was constructed at the downstream toe of each embankment.

From 12 through 14 July 2012, 22 years after the event described above, another, more severe rainfall attacked these sites (Fig. 30). The total precipitation during a period from early morning 12 July till evening 14 July reached $816.5 \mathrm{~mm}$ with a peak of $500 \mathrm{~mm}$ for $5 \mathrm{~h}$ and $106 \mathrm{~mm} / \mathrm{h}$, which was much more intense than the 1990 heavy rainfall with a total precipitation of $650 \mathrm{~mm}$ and a peak of $67 \mathrm{~mm} / \mathrm{h}$. A number of embankments that did not collapse by the 1990 heavy rainfall were seriously damaged or totally collapsed by scouring, erosion by over-topping flood and seepage flow of rain water likely with a loss of suction followed by the development of positive pore water pressure. The total number of the damage sites of the railways of JR Kyushu was 201, among which 133 sites were along Ho-Hi Line, including the sites described in Figs. 30 and 31 . The total damage cost exceeded five billion yen.

The three major geosynthetic-reinforced (GR) embankments that were reconstructed in 1991 were attacked by over-topping flood due to clogging of the 3-m-diameter 
Fig. 25 a Collapse of cantilever RW by scouring in the supporting ground and $\mathbf{b}$ stable performance of GRS RW with FHR facing
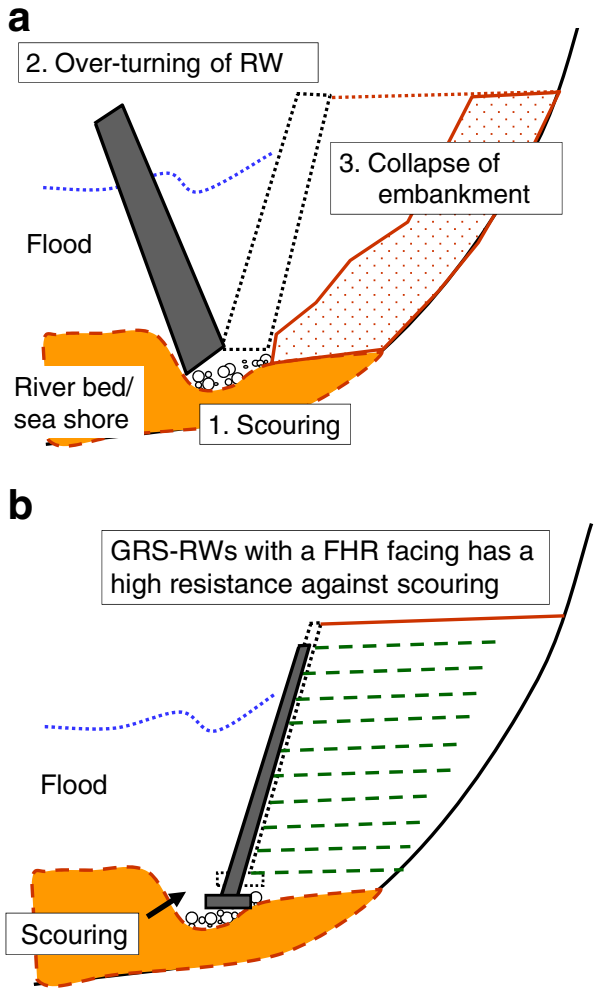

corrugate drain pipes by mudflow from the upper reach. However, the main body of these GR embankments survived only with partial erosion, despite that they were not designed against such over-topping flood. In Fig. 31a, at site 2, the left-hand part of the embankment located between two tunnel exits is unreinforced backfill as it survived the 1990 flood and basically remained unchanged. This part was severely eroded by the overtopping flood by the 2012 rainfall (Fig. 31b). In the left part of Fig. 31c, the eroded part of the unreinforced embankment had been excavated to some extent for restoration works that were performed at later stages.

On the other hand, the right-hand part of the embankment seen in Fig. 31a is located at the deepest place of the valley. This part was fully eroded by the 1990 flood and reconstructed to a GRS structure (Fig. 29). The exposed cross-section of the GR embankment is shown in Fig. 31d. This part performed very well during the 2012 heavy rainfall: i.e., it may be seen from Fig. 31c that only some surface layer of the downstream slope of the GR embankment were eroded. Although relatively deep gullies were formed in the unprotected downstream slope of the GR embankment, the development of these gullies stopped at some stage due likely to the resistance of geogrid layers against erosion. As seen from Fig. 30, during the 2012 flood, debris flows did not attack the houses at the downstream reach of the embankments, due to the barriers constructed in 1991 as well as a limited scale of failure of the GR embankments of the railway. The reconstruction of the damaged embankments to GRS structures was completed by the end of August 2013. 
Fig. 26 Seawall for Seisho by-pass of National Road No. 1 in Kanagawa Prefecture, southwest of Tokyo: a collapse for a length of about $1.5 \mathrm{~km}$ by Typhoon No. 9, 29 August 2007; b a typical cross section of GRS RW; and $\mathbf{c}$ GRS RW under construction (a, b by the courtesy of the Ministry of Land, Infrastructure, Transport and Tourism)

Collapse of Coastal Dikes and Bridges by Tsunami and Their Restoration

By the 2011 Great East Japan Earthquake, massive tsunami brought destruction along the Pacific coastline of East Japan. Coastal dikes at many places fully collapsed by the following mechanism caused by deep overtopping tsunami current (Fig. 32): (1) The ground in front of the toe of the downstream slope was scoured. The concrete panels at the crest and around the downstream corner at the crest were lifted up by the tsunami current. (2) The stability of the concrete panels on the crest and the downstream slope, which were not fixed to the backfill, was lost and washed away. (3) The erosion of the backfill started, eventually the backfill was fully washed away and the full section was lost. As a result, the dikes could not work at all as a barrier against subsequent tsunamis. On the other hand, small scale model tests [39] indicated that coastal dikes that comprise the geogrid-reinforced backfill covered with continuous lightly steel-reinforced concrete facings firmly connected to the reinforcement, such as those illustrated in Fig. 33, have much stronger resistance against deeply over-topping tsunami current.

The girders and/or approach fills behind the abutments of a great number of road and railway bridges (more than 340) were washed away by the great tsunami [40], as typically seen from Figs. 34 and 35a. It was confirmed that a girder supported by bearings has a very low resistance against uplift and lateral forces of tsunami current while the unreinforced backfill is easily eroded by overtopping tsunami current. In many cases, the connectors and anchors that had been arranged to prevent dislodging of the girders from the abutments and piers by seismic loads could not prevent the flow away of the girders by tsunami forces. These cases showed that the girder bearings and unreinforced backfill are two major weak points of the conventional-type bridges not only for seismic loads but also for tsunami loads. The results of small scale model tests [41] support this feature.

Tatsuoka and Tateyama [9] proposed to construct GRS integral bridges (Fig. 21) and GR embankments/dikes (Fig. 33) to restore the conventionaltype bridges and embankments of railways and roads that collapsed by the great tsunami of the 2011 Great East Japan Earthquake. Small model tests [41] indicated that, due to a high structural integrality, GRS integral bridge has a much higher resistance against tsunami current than conventional-type bridges.

Sanriku Railway, opened 1984, is running along the coastline where the tsunami damage was very serious. In particular, the three bridges located between tunnels in narrow valleys facing the Pacific Ocean at three sites just south of the site shown in Fig. 32b totally collapsed. Figure 35a shows one of these three sites. Tsunami loads were particularly large with these bridges because (a) the track level is lowest $(12.3-14.5 \mathrm{~m})$ at these three sites along 
a

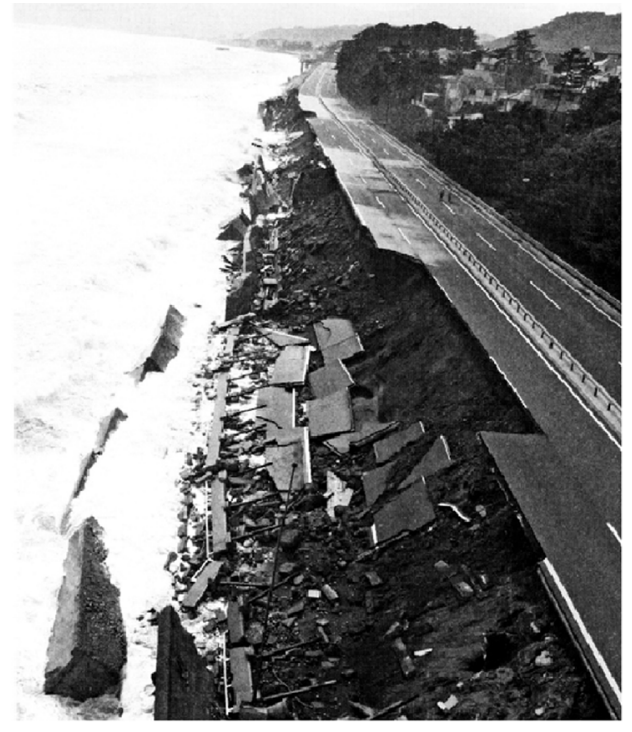

b
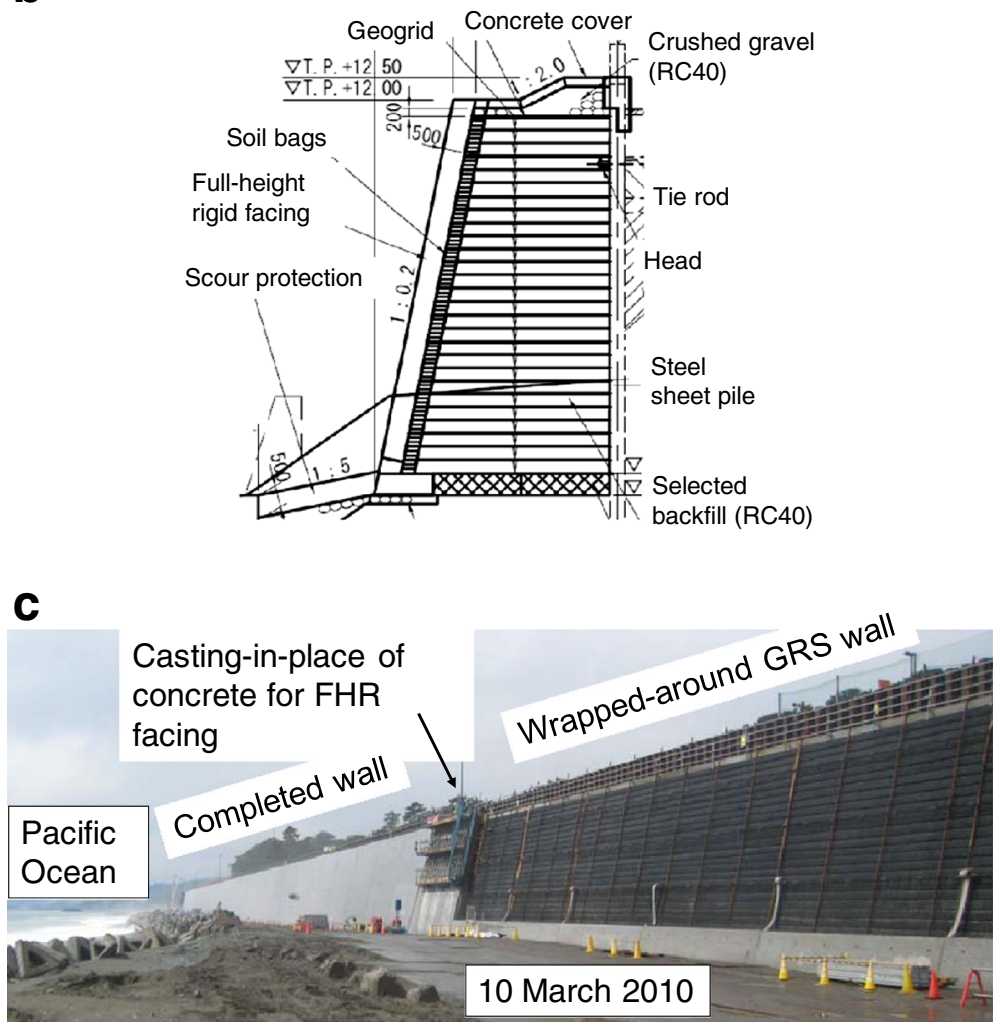
Fig. 27 a Collapse of a masonry RW for the approach fill of a bridge by scouring of the supporting ground, followed by erosion of the backfill by flood, July 2011, and b-d restoration to a GRS RW with FHR facing, Iiyama Line, JR East [38] a

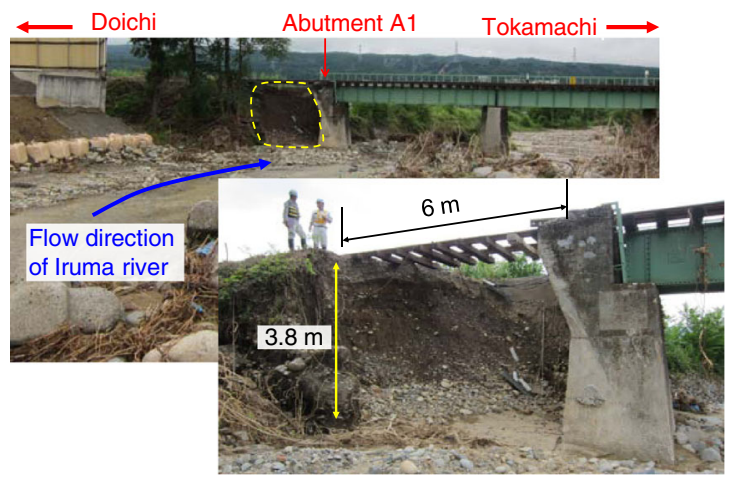

b

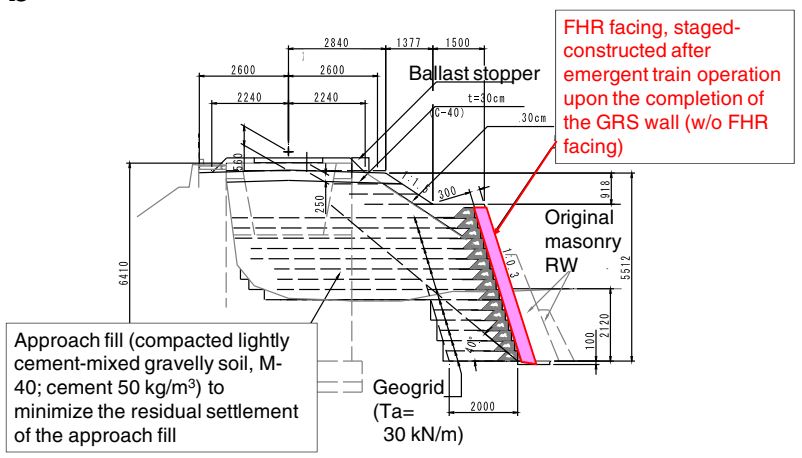

C

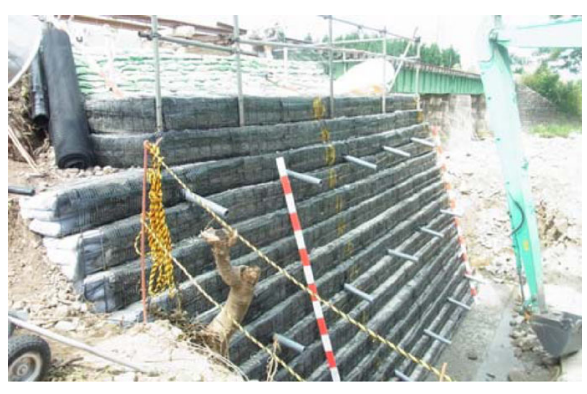

d

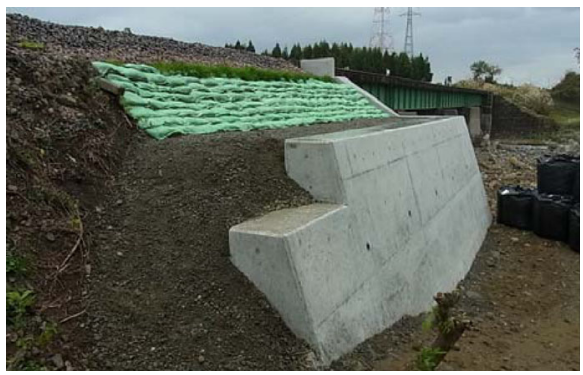



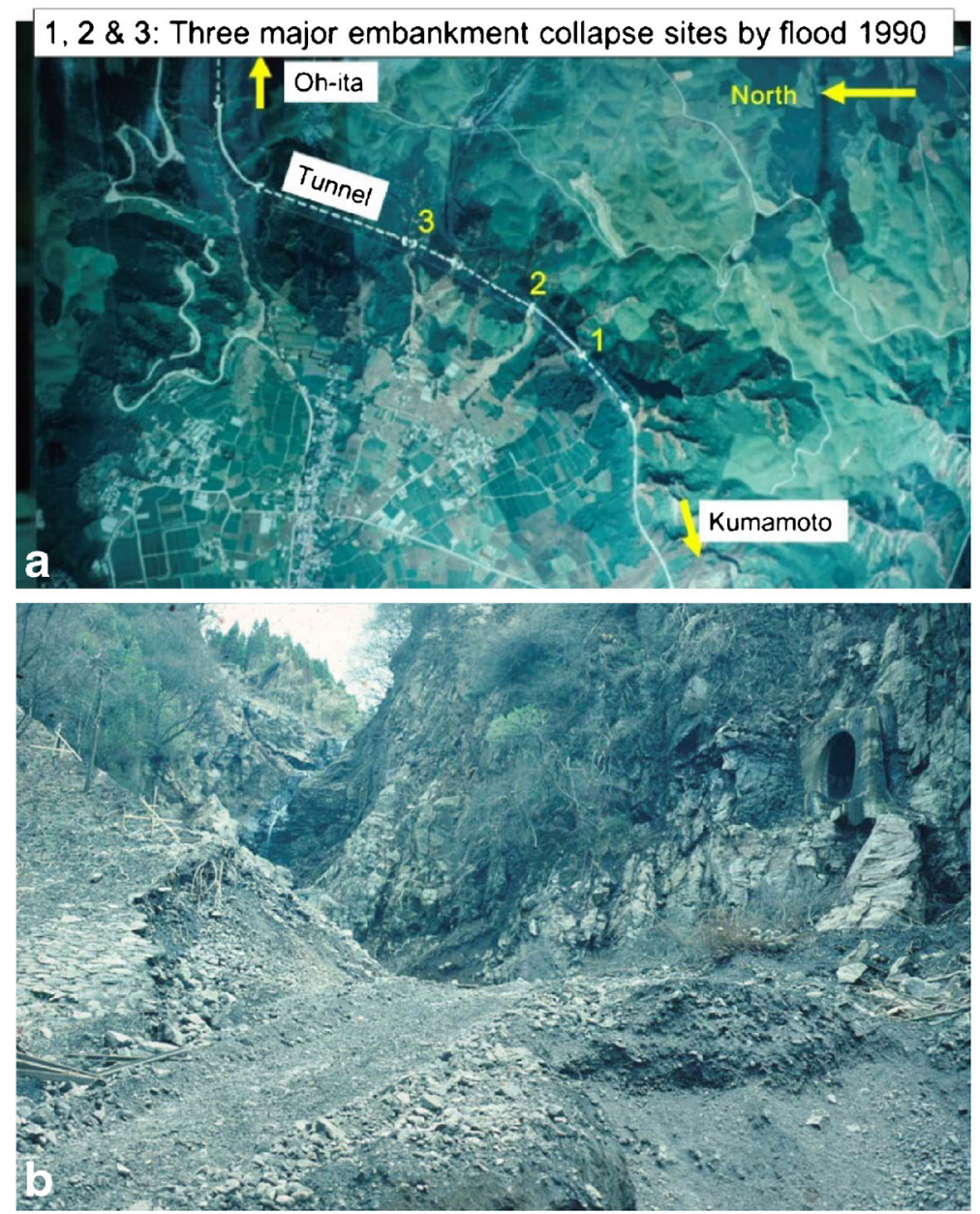

Fig. 28 a Locations of three major embankment failures by heavy rainfall in 1990 (site B in Fig. 6a), Ho-Hi Line, JR Kyushu, and $\mathbf{b}$ a view from the downstream at site 2 [1]

this railway, (b) the sites are closest to the coastal line (see Fig. 35a), and (c) there was no coastal dike between the railway and the coastal line at these sites. Based on the successful case histories described in the preceding sections and considerations that GRS integral bridges should have a high resistance against tsunami, it was decided to construct GRS integral bridges to restore these three bridges. Figure $35 \mathrm{~b}-\mathrm{d}$ shows one of the three GRS integral bridges. The total span length is $60 \mathrm{~m}$, which is much longer than the one at Kikonai (Fig. 23). Figure 35e shows one of the two abutments during construction seen from the inland side.

Figure 36a shows Shima-no-koshi Station of Sanriku Railway before the earthquake. The level of the railway track at the site was about $14 \mathrm{~m}$ from the sea level. This track level was determined based on the previous tsunami disasters in 1896 and 1933. However, the tsunami height this time was much higher $(22-23 \mathrm{~m}$ at this site) and the tunnel was inundated (Fig. 30c). The RC framework structure was 
Fig. 29 a Cross section; b a view during reconstruction in 1991; and $\mathbf{c}$ a view in 1994 of the reconstructed GR embankment. Site 2 in Figs. 28a and 30 of Ho-hi Line, JR Kyushu

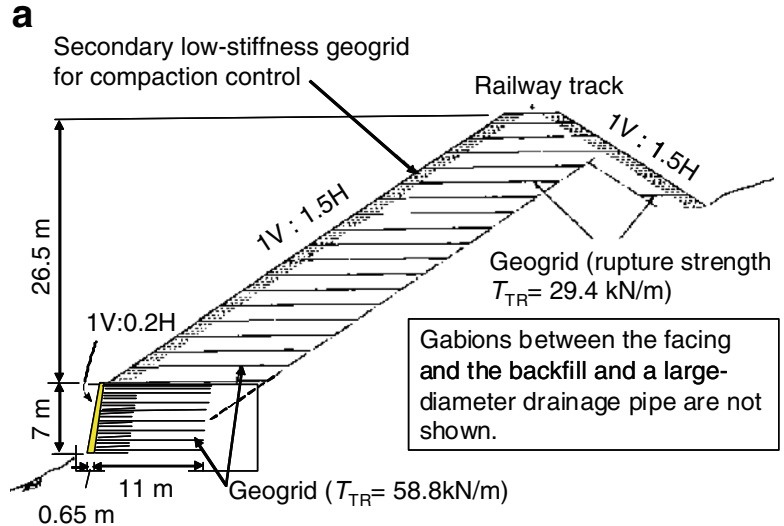

b

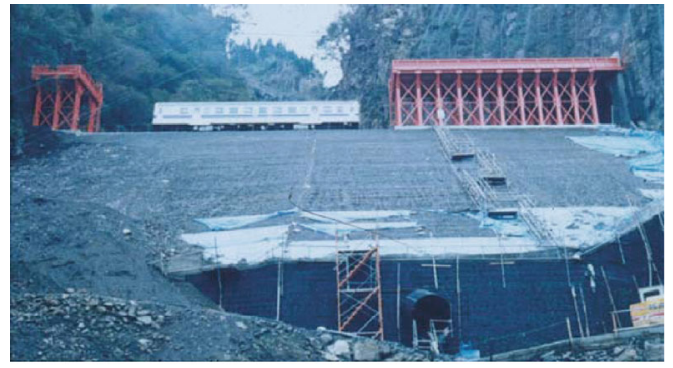

C

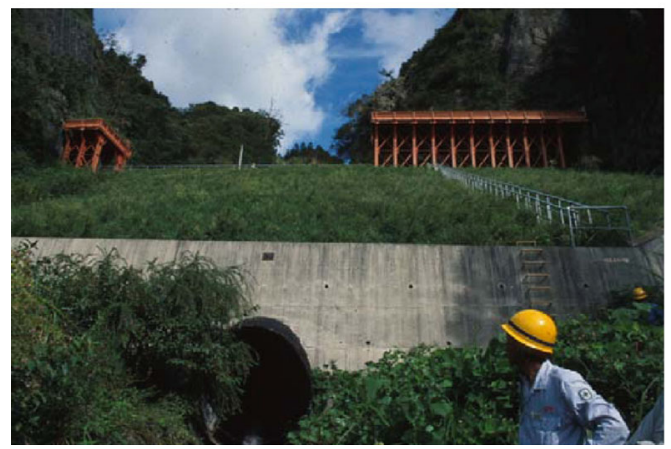

seriously damaged and the station was totally washed away (Fig. 36b). On the request of the residents at the site, GR embankment was constructed as a tsunami barrier following the proposal shown in Fig. 33 in place of the previous RC framework structure (Fig. 37a). Figure 37b shows the representative cross-section of the GR embankment and Fig. 37c shows a view of the completed GR embankment. Both slopes of the embankment are covered with lightly steel-reinforced concrete facing firmly connected to the geogrid layers reinforcing the backfill. The restoration work at the site includes the construction of another GRS integral bridge (Fig. 37d). The bridge is covered with a backfill layer to reduce as much as possible the size of the opening. Figure $37 \mathrm{e}$ 


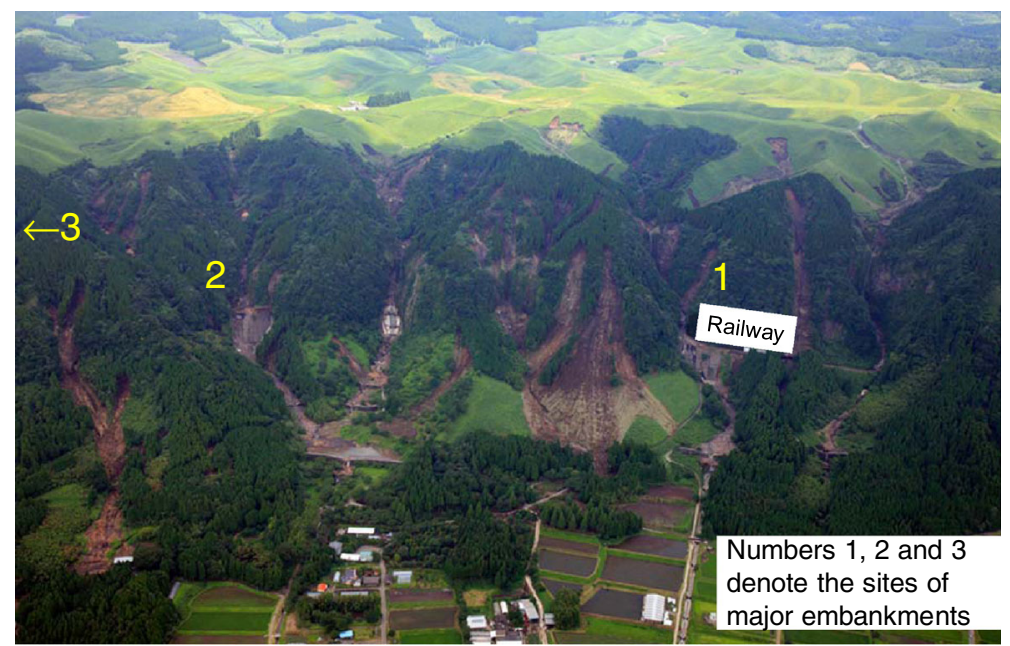

Fig. 30 Aerial photograph of Ho-hi Line immediately after the 2012 heavy rainfall. The picture was provided by PASCO Corporation (http://www.pasco.co.jp/disaster_info/120713/)

shows the completed GRS integral bridge and RC box culvert, seen from the sea side.

Based on the experiences described above, it can be recommended to adopt such GRS structures as described in this section for railway and road structures that are required to be designed against severe earthquakes and strong tsunami currents.

\section{Importance of Relevant Redundancy}

One of the important lessons that can be learned from the case histories described above and others is that: (1) some relevant redundancy should be intentionally introduced at the design stage to prevent collapse by unpredictable extreme loads and (2) the redundancy that the GRS structure inherently has may explore new applications.

The case history that most typically shows the importance of relevant redundancy is the GRS RW with FHR facing at Tanata (Fig. 8). The wall survived level 2 seismic load during the 1995 Great Kobe Earthquake, despite that the wall had been designed against much lower seismic load (level 1): i.e., a minimum overall safety factor equal to 1.5 evaluated by the limit equilibrium analysis was required for a horizontal seismic coefficient equal to 0.2 . It is very likely that, in addition to the use of overall safety factor higher than 1.0, the following four factors of redundancy prevented the collapse of the wall [13].

1. The design friction angle $\phi$ for the backfill (well-graded sandy soil) was a default value (i.e., $35^{\circ}$ ). As seen from Fig. 38c, this $\phi$ value corresponds approximately to a degree of compaction $D_{\mathrm{c}}$ (standard Proctor) equal to $90 \%$. This $D_{\mathrm{c}}$ value was the allowable lower limit for all measured values in the field compaction control in this 
Fig. 31 a Cross section; b a view during reconstruction in 1991; and $\mathbf{c}$ a view in 1994 of the reconstructed GR embankment. Site 2 in Figs. 28a and 30 of Ho-hi Line, JR Kyushu
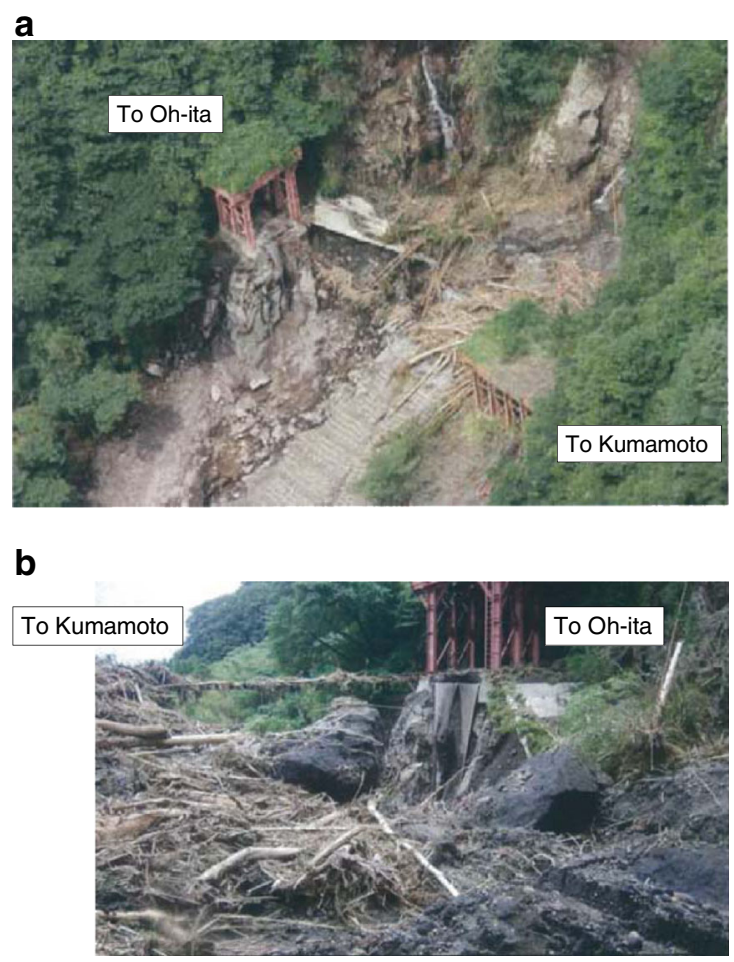

C
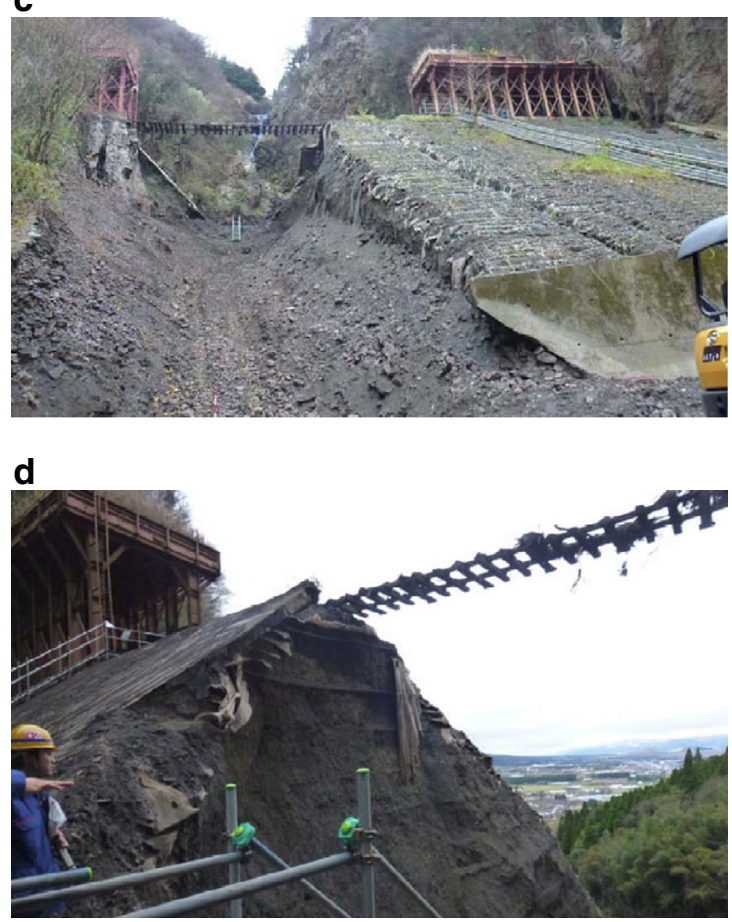


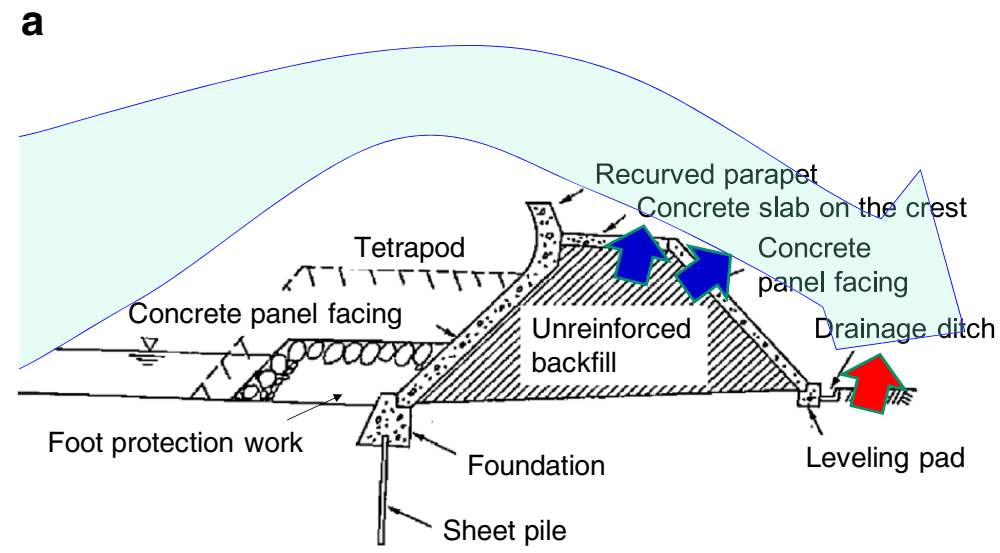

b

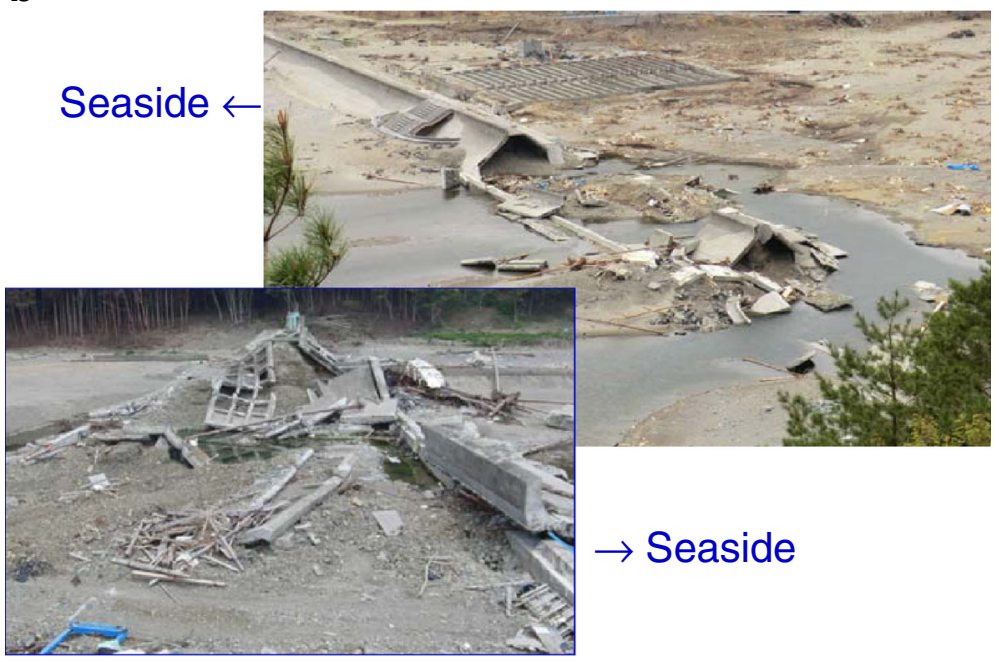

Fig. 32 a Failure mechanism of coastal dikes by overtopping tsunami current; b typical fully collapsed coastal dike, Aketo, Tanohara, Iwate Prefecture (site C in Fig. 6a) [44]

case. Therefore, the average of the actual $D_{\mathrm{c}}$ values of the backfill of the wall should have been much higher. Tatsuoka et al. [13] inferred $\phi=42^{\circ}$ as a realistic peak value in this case. As seen from Fig. 38d, the drained strength expressed in terms of $\phi_{\text {peak }}=\arcsin \left\{\left(\sigma_{1}-\sigma_{3}\right) /\left(\sigma_{1}+\sigma_{3}\right)\right\}_{\text {peak }}$ of backfill as moist as when compacted becomes higher than the one of saturated backfill to more extent with an increase in the compacted dry density. This is due to effects of capillary suction. Then, an apparent cohesion $c$ due to the matrix suction is obtained when fitting a linear failure envelope to a multiple Mohr's circles at the peak stress state at different confining pressure. In the design of the wall, the apparent cohesion $c$ was ignored. However, its effect on the seismic stability of the wall could have been significant with this wall, as it had been no major rainfalls for a long period by the time of the earthquake and the backfill was a well-graded sandy soil with a fines content of about $9 \%$. 


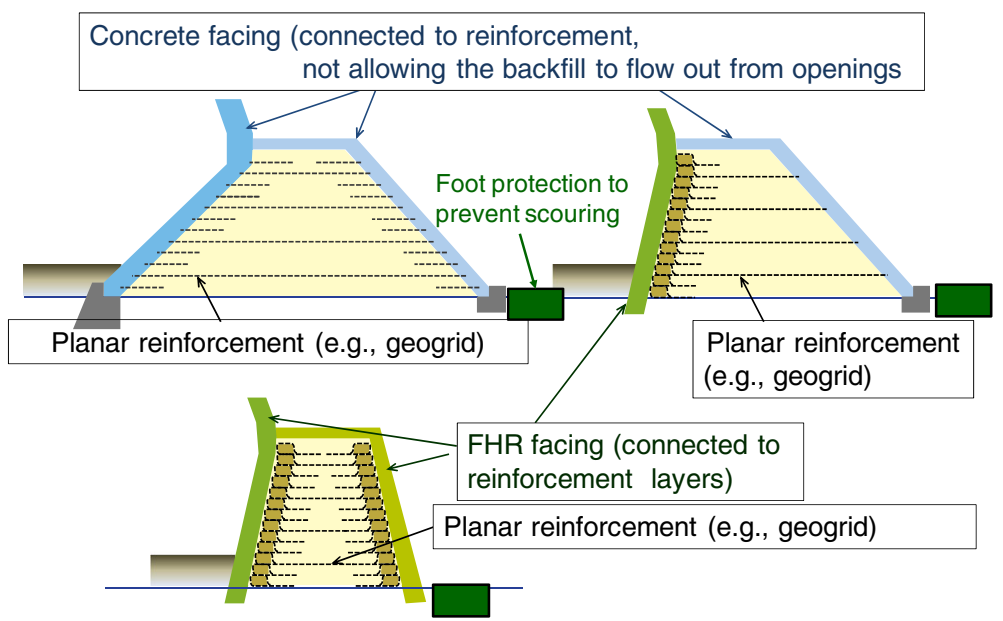

Fig. 33 GRS coastal dikes as a tsunami barrier designed to survive deep over-topping tsunami current [44]

2. The toe resistance was ignored, although it is very likely that this factor was not negligible (see Fig. 8).
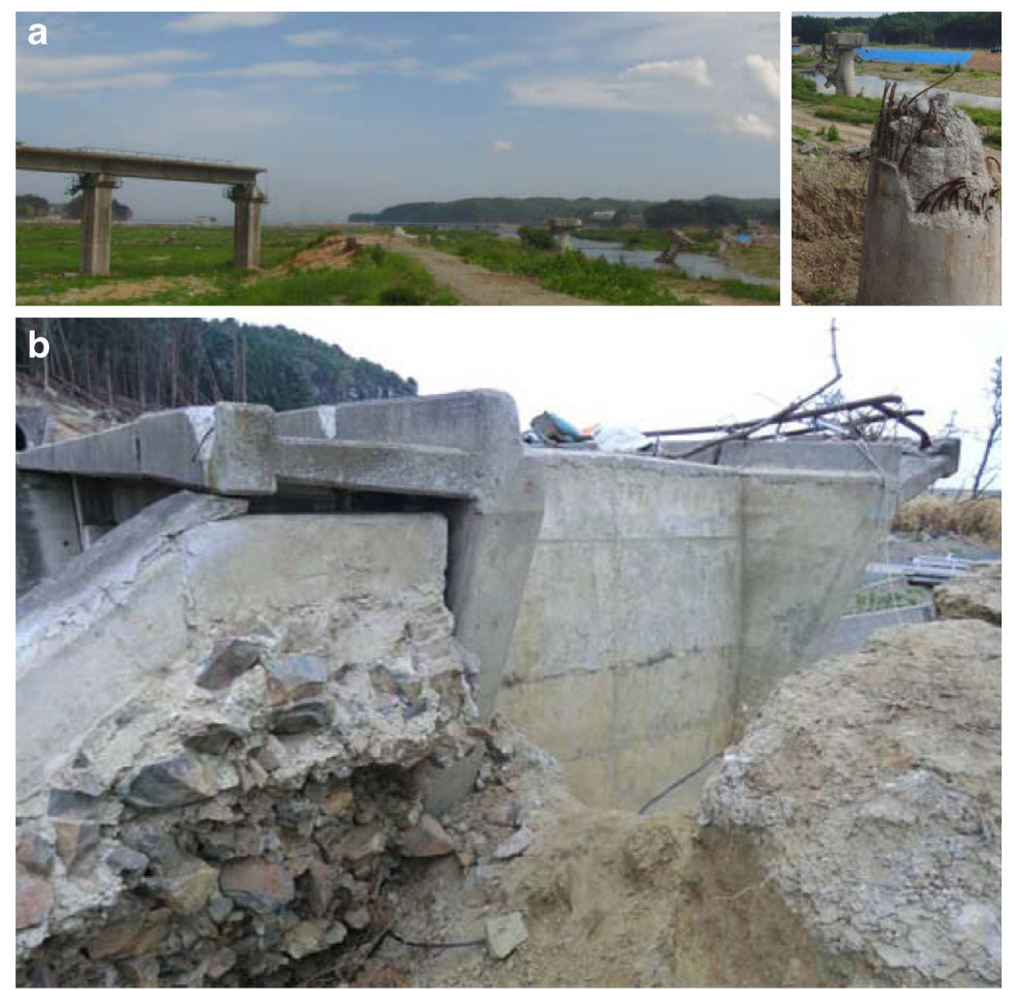

Fig. 34 a Tsuyano-kawa Bridge, JR East Kesen-numa Line, that lost multiple simple-supported girders by tsunami forces and $\mathbf{b}$ a view of the back of the right bank abutment of Yonedagawa Bridge, Noda, Iwate Prefecture, North-Rias Line, Sanriku Railway [44] 
3. It was considered that the wall collapses immediately when the calculated overall safety factor reaches 1.0 by assuming that the specified horizontal seismic load acts persistently in the active direction (i.e., not cyclic loading). However, in actuality, unacceptable residual deformation/displacements may develop only after the calculated overall safety factor becomes lower than 1.0 for a certain period during cyclic seismic loading.

The second case history is the geosynthetic-reinforced railway embankments that survived over-topping flood by the 2012 heavy rainfall (Fig. 31). At the stage of design after the disaster by the 1990 heavy rainfall, overtopping flood in the future was not anticipated, assuming that a 3-m-diameter drain pipe is sufficient. The collapse of geosynthetic-reinforced embankments by the 2012 heavy rainfall was prevented due likely to redundancy resulting from geosynthetic-reinforcing of the backfill that was adopted to reduce the amount earthwork by making the embankment slope steep while ensuring a sufficiently high stability. The GR embankments exhibited unexpectedly high resistance against erosion by over-topping flood due to its inherent high integrality.

The third case history is the GRS integral bridges that were constructed to restore three railway bridges that fully collapsed by tsunami during the 2011 Great East Japan Earthquake (Figs. 35, 36, and 37). The GRS integral bridge technology had been developed aiming at a lower cost for construction/longterm maintenance and a higher seismic stability, not aiming at a high resistance against tsunami loads. However, the GRS integral bridges were adopted expecting a high stability against not only seismic loads but also tsunami loads resulting from a high structural integrality among the girder, facing, and reinforced backfill.

The relevant redundancy addressed above is the safety margin that is not covered by the safety factor that is always used in design. These case histories indicate that the introduction of relevant redundancy is essential to reduce the risk of failure/collapse of soil structures by unusual, extreme events that may take place in the future, the whole of which cannot be predicted at the stage of design. The authors believe that it becomes possible to retain a relevant amount of redundancy only by such good structure, good design, and good construction as described below:

1. Good structure by the following factors:

(a) High structural strength: i.e., large load is necessary to start failure.

(b) High structural ductility: i.e., large energy is necessary to reach full collapse after the start of failure.

(c) High structural integrality: i.e., local failure does not easily result into the collapse of whole structure.

These factors can be realized by means of GRS structures described in this paper much more cost-effectively than conventional-type soil structures. Factor a is usually expressed by the global structural safety factor evaluated by the limit equilibrium analysis. Factor $b$ can be expressed at least partially by the residual deformation evaluated by the Newmark method, for example. Factor $\mathrm{c}$ is usually not evaluated in the current 
Fig. 35 a Fully collapsed conventional type bridge; b plan of GRS integral bridge seen from the seaside (under construction); c representative cross sections; d under construction (3 November 2013); and e the abutment at the right side in b during construction (23 May 2013), Haipe (site C in Fig. 6a), Sanriku Railway

design practice; thus, this could be one of the major sources for redundancy.

2. Good design at least by the following means:

(a) Relevant seismic design is done for soil structures in seismic zones. Relevant seismic design also improves long-term performance under static conditions (i.e., small residual deformations). Some soil structures that are not seismicdesigned may survive seismic loads lower than a certain limit. This should be due to redundancy that those soil structures have under ordinary static conditions. However, such case histories observed under limited conditions as above cannot warrant no-seismic design of all soil structures for seismic loads lower than a certain limit. In fact, a number of soil structures, including reinforced soil walls, were seriously damaged or fully collapsed during previous earthquakes, due likely to no or no serious seismic design and associated low level of seismic stability (e.g., [10-13, 31, 42). No seismic design policy will result into a global reduction of redundancy; thus, a global level down of the stability of soil structures in general and, therefore, will increase the number of failure/collapse.

(b) With GRS RWs, relevant facing structure and firm facing/reinforcement connection, in addition to relevant geosynthetic reinforcement arrangement, is essential [43].

(c) The whole of the redundancy created by the adoption of good structure and the execution of good construction (described below) should not be fully taken into account in the stability analysis in design, but part of the created redundancy should be preserved by using conservative soil shear strength, ignoring the apparent cohesion and toe resistance and others. The use of $\phi_{\text {peak }}$ in addition to $\phi_{\text {residual }}$ is to give reward for good compaction while it reduces the redundancy. However, at the same time, the redundancy may increase as this reward encourages good compaction. Even in this case, the design values of $\phi_{\text {peak }}$ should be determined conservatively. Moreover, taking into account positive effects of structural ductility on the stability based on residual deformation of soil structure, for example, also reduces the redundancy. However, this is only partial evaluation of structural ductility while positive effects of structural integrality are not evaluated in the current design. Therefore, the evaluation of structural ductility in design encourages the adoption of soil structures having larger structural ductility and integrality, therefore, those having more redundancy.

3. Good construction by the following means:

(a) Use of good backfill, as much as possible.

(b) Good compaction, encouraged by the use of $\phi_{\text {peak }}$.

(c) Good drain, by which it can be expected that no positive pore water pressure develops even during heavy rains with walls constructed in water collecting 
a

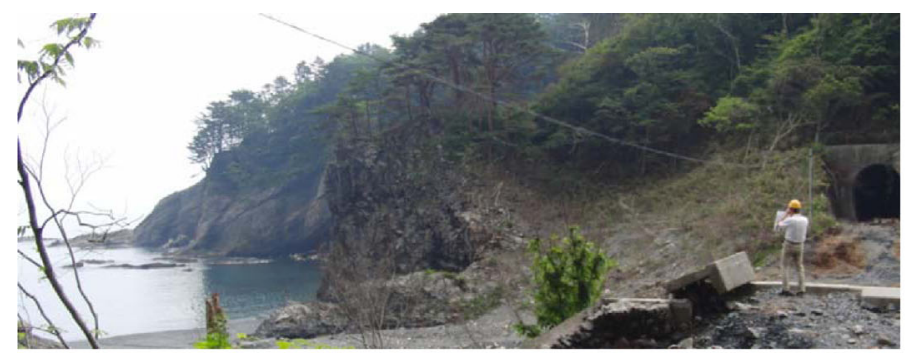

b

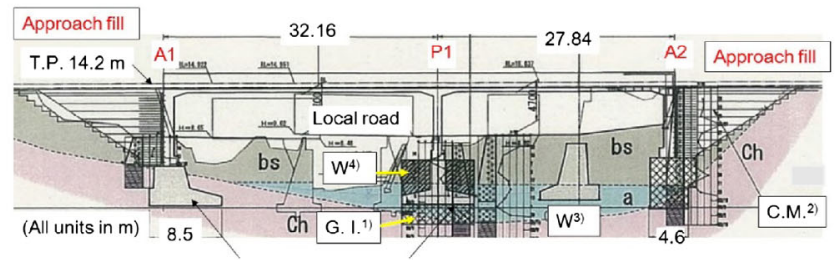

The foundations of the abutments and pier that survived the earthquake are used as the foundations for GRS integral bridge.

1) Ground improvement by jet-grouting of cement-slurry.

2) Cement-mixed backfill. 3) The top part of this pier was removed.

4) Cast-in-place concrete mass

C

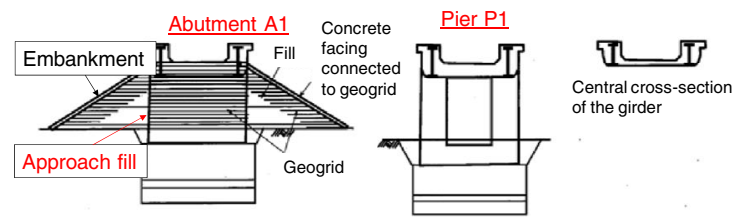

\section{d}

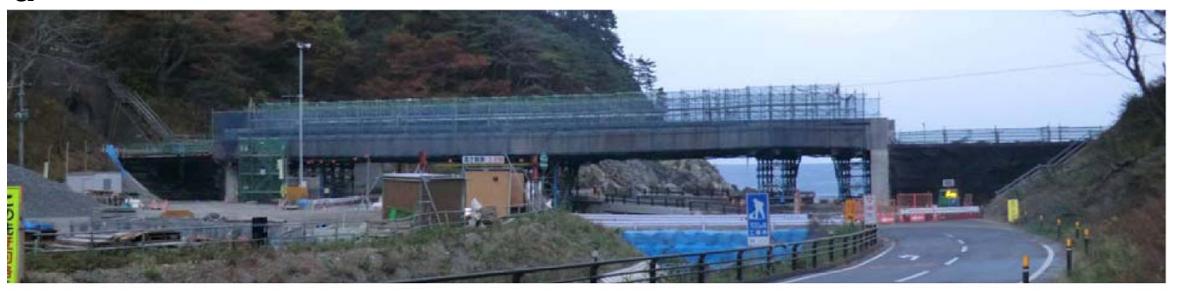

e

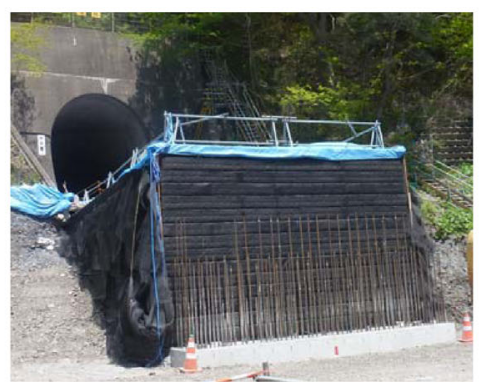


a

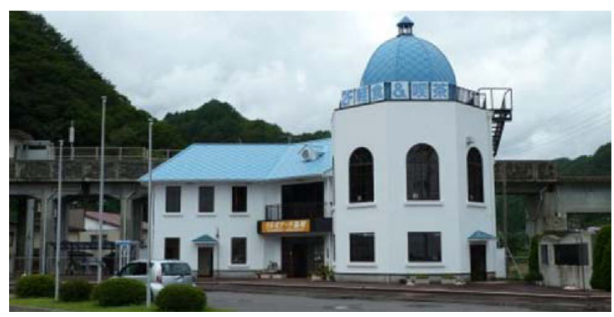

b

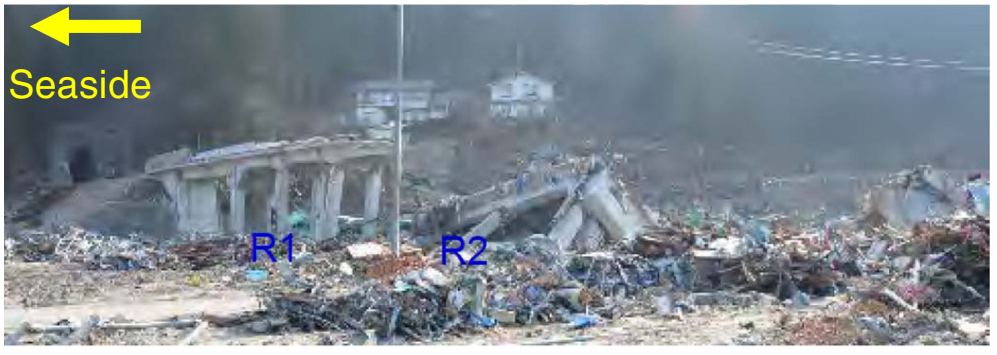

C

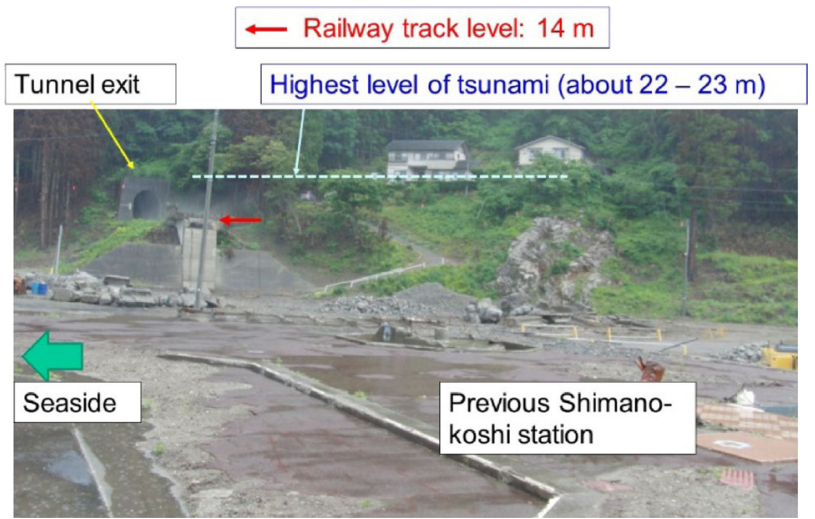

Fig. 36 a A view before the earthquake; b a view immediately after the earthquake; and c a view 14 July 2013, Shimano-koshi Station (site C in Fig. 6a), Sanriku Railway

places. Good compaction with good drain may result in significant suction even in such cases as above. This factor is also related to the issues of good structure and good design.

In summary, high redundancy can be produced only by a combination of good structure, good design, and good construction. Highly redundant soil structures perform well under extreme conditions. Very importantly with the GRS structures described in this paper, the cost of this redundancy can 
a

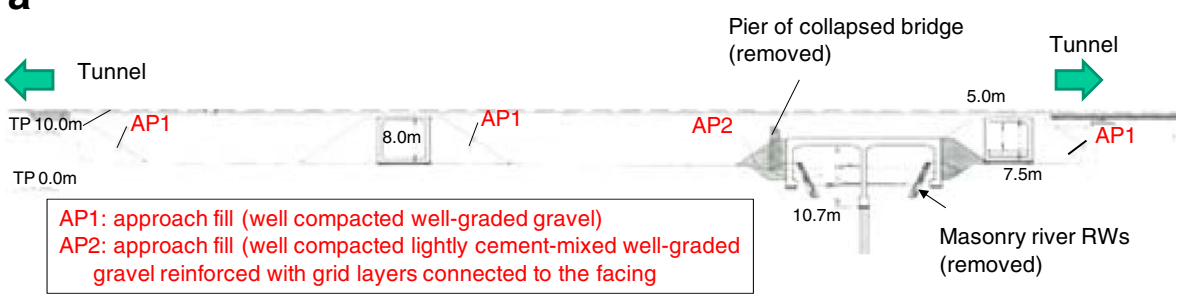

b

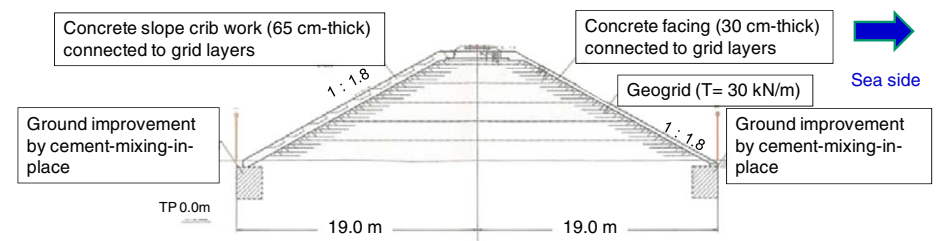

C

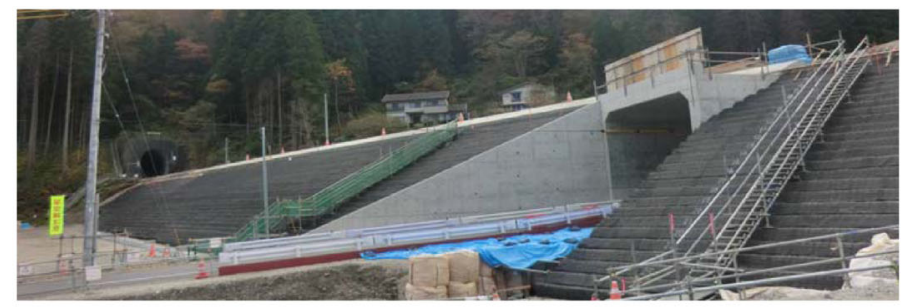

d

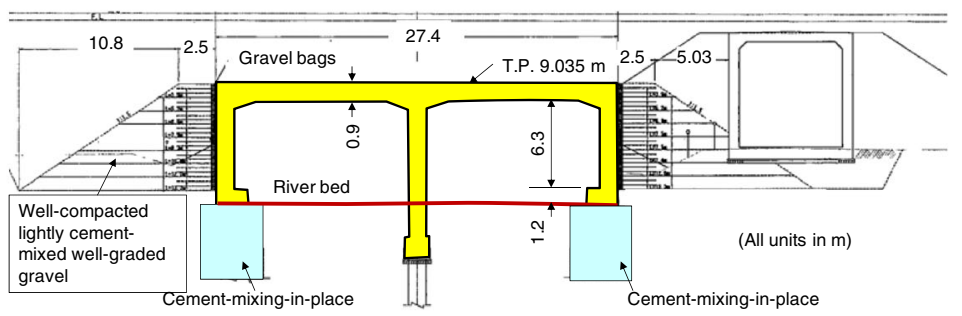

e

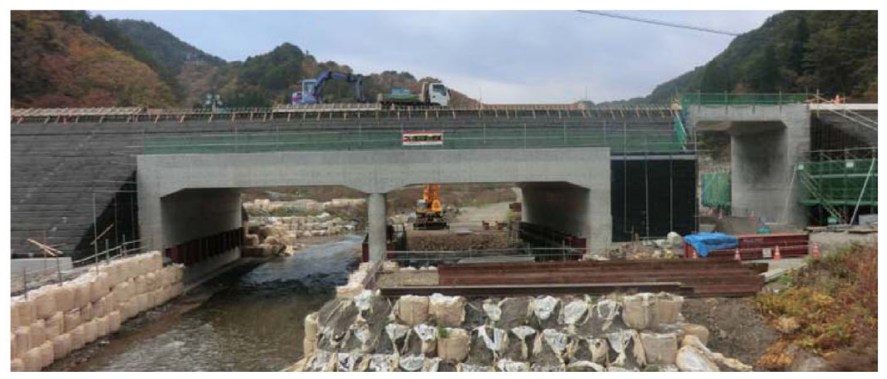

Fig. 37 a Overall plan of GRS structures; b representative cross section of GR embankment; c embankment (3 November 2013); d GRS integral bridge; and e GRS integral bridge and RC box culvert during construction (3 November 2013) (a, c, and d seen from the seaside), Shimano-koshi Station (site C in Fig. 6a), Sanriku Railway 
a

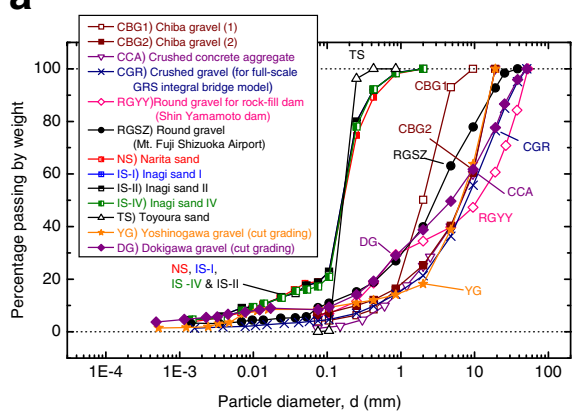

b

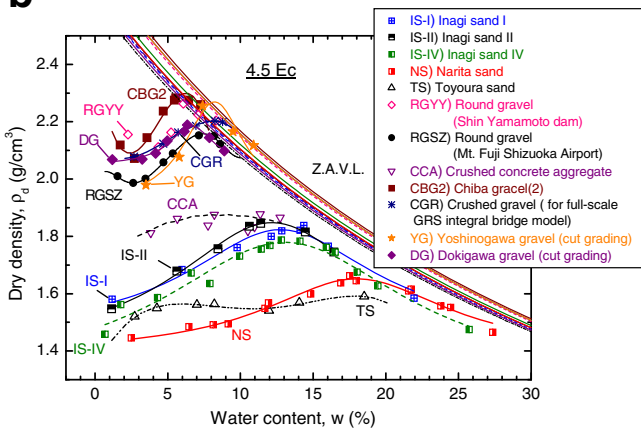

C

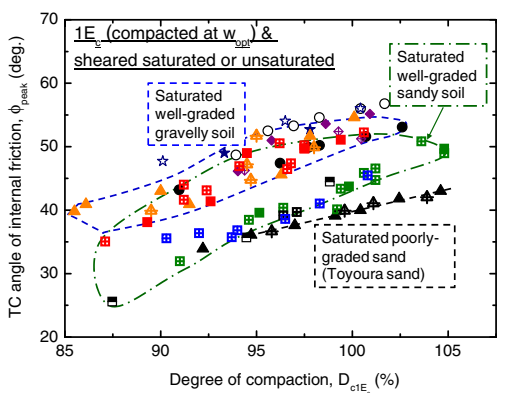

d

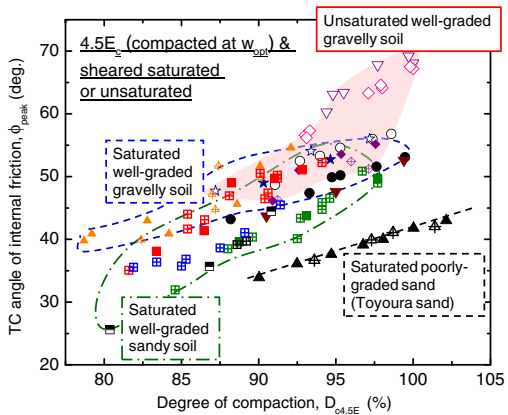

Fig. 38 a Grading curves; $\mathbf{b}$ compaction curves; $\mathbf{c}$ peak friction angle $\phi_{\text {peak }}=\arcsin \left\{\left(\sigma_{1}-\sigma_{3}\right) /\left(\sigma_{1}+\sigma_{3}\right)\right\}_{\text {peak }}$ plotted against the degree of compaction defined for standard Proctor (1Ec) (saturated specimens); and $\mathbf{d}$ modified Proctor ( $4.5 \mathrm{Ec}$ ) (saturated and moist specimens), from a series of drained triaxial compression tests at confining pressure of $50 \mathrm{kPa}$ of sandy and gravelly soils compacted at the optimum water content [45]

outweigh the cost of failure/collapse and increased maintenance, while their construction cost is usually lower than respective corresponding conventionaltype soil structures (i.e., RWs and bridge abutments).

\section{Conclusions}

A number of GRS RWs having a stage-constructed FHR facing have been constructed as important permanent RWs in Japan. It is now the standard RW technology for railways, including high-speed train lines. Other types of GRS structure, including GRS integral bridges and GRS coastal dikes, were developed based on this GRS RW technology. The following conclusions can be derived from the case histories described above:

1. The current popular use of GRS RWs with FHR facing for railways is due to a high cost-effectiveness (i.e., low construction/maintenance cost, high construction speed, and high stability), in particular high performance during severe earthquakes. 
2. The GRS integral bridge, comprising a continuous girder of which both ends are structurally integrated to the top of the facing of a pair of GRS RWs, has high resistance against seasonal thermal expansion and contraction of the girder, severe seismic loads, and tsunami loads, while it is highly cost-effective. As demonstrated by several case histories, it can be expected that this new bridge type is adopted in many other cases.

3. The recent seismic design of Japanese railway soil structures, including GRS RWs and GRS integral bridges, are characterized by the following: (1) introduction of very high design seismic load (level 2), (2) the use of peak and residual shear strengths with well-compacted backfill (while ignoring apparent cohesion), (3) design based on the limit equilibrium stability analyses, (4) evaluation of seismic performance based on residual deformation obtained by modified MononobeOkabe and Newmark methods, (5) no creep reduction factor for the design tensile rupture strength of geosynthetic reinforcement against seismic loads, and (6) recommendations of the use of GRS structures when relevant and possible.

4. A number of conventional-type soil structures (i.e., embankments and RWs) that collapsed by earthquakes, heavy rains, floods, and storm wave actions were reconstructed to GRS RWs with FHR facing. This standardized practice is due also to a high cost-effectiveness of this type of GRS RW.

5. By the great tsunami during the 2011 Great East Japan Earthquake, a great number of coastal dikes were fully eroded, and a great number of bridges running along the seashore lost their girders and/or approach fills. GRS coastal dikes covered with continuous facing connected to geogrid layers reinforcing the backfill can perform much better than the conventional type, surviving both high seismic loads and subsequent deep over-topping tsunami current. Geosynthetic-reinforced embankments that function also as coastal dikes and GRS integral bridges were constructed to restore a railway that was seriously damaged by the great tsunami.

6. The GRS structures described in this paper can be and have been designed and constructed to have high redundancy so that they perform well under extreme conditions and it has been the case as demonstrated by a number of case histories. With these GRS structures, the cost of this redundancy outweighs the cost of failure/collapse and increased maintenance.

Acknowledgments The authors deeply appreciate cooperation provided by their previous and current colleagues at University of Tokyo, Tokyo University of Science, Railway Technical Research Institute, and Japan Railway Construction, Transport and Technology Agency in performing this long-term investigation.

\section{References}

1. Tatsuoka, F., Tateyama, M., Uchimura, T., Koseki, J.: Geosynthetic-reinforced soil retaining walls as important permanent structures, Mercer Lecture. Geosynth. Int. 4(2), 81-136 (1997)

2. Tatsuoka, F.: Geosynthetics engineering, combining two engineering disciplines, Special Lecture. Proc. GeoSyntheticsAsia, Shanghai 2, 1-35 (2008) 
3. Aoki, H., Yonezawa, T., Tateyama, M., Shinoda, M., Watanabe, K.: Development of a seismic abutment with geogrid-reinforced cement-treated backfill, Proc. 16th IC on SMGE, Osaka, pp.1315-1318 (2005)

4. Tatsuoka, F., Tateyama, M., Aoki, H., Watanabe, K.: Bridge abutment made of cement-mixed gravel backfill, Ground Improvement, Case Histories, Elsevier Geo-Engineering Book Series, Vol. 3 (Indradratna \& Chu eds.), pp.829-873 (2005)

5. Tatsuoka, F., Hirakawa, D., Nojiri, M., Aizawa, H., Tateyama, M., Watanabe, K.: Integral bridge with geosynthetic-reinforced backfill, Proc. First Pan American Geosynthetics Conference \& Exhibition, Cancun, Mexico, pp.1199-1208 (2008a)

6. Tatsuoka, F., Hirakawa, D., Aizawa, H., Nishikiori, H. Soma, R., Sonoda, Y.: Importance of strong connection between geosynthetic reinforcement and facing for GRS integral bridge, Proc. 4th GeoSyntheticsAsia (4th Asian Regional Conference on Geosynthetics), Shanghai (2008b)

7. Tatsuoka, F., Hirakawa, D., Nojiri, M., Aizawa, H., Nishikiori, H., Soma, R., Tateyama, M., Watanabe, K.: A new type integral bridge comprising geosynthetic-reinforced soil walls. Gesynthtetics International, IS Kyushu 2007 Special Issue 16(4), 301-326 (2009)

8. Tatsuoka, F., Kuroda, T., Tateyama, M.: Research and practice of GRS integral bridges, Proc. EuroGeo 5, Valencia, September, pp.177-181 (2012)

9. Tatsuoka, F., Tateyama, M.: Geosynthetic-reinforced soil structures for railways in Japan, Keynote Lecture, Proc. International Conference on Ground Improvement and Ground Control (ICGI 2012) (Indraratna et al., eds.), pp. 43-56 (2012a)

10. Koseki, J., Bathurst, R.J., Guler, E., Kuwano, J., Maugeri, M.: Seismic stability of reinforced soil walls, Proc. 8th International Conference on Geosynthetics, Yokohama, 1: pp. 51-77 (2006)

11. Koseki, J., Tateyama, M., Watanabe, K., Nakajima, S.: Stability of earth structures against high seismic loads, Keynote Lecture, Proc. 13th ARC on SMGE, Kolkata, Vol. II (2008)

12. Koseki, J.: "Use of geosynthetics to improve seismic performance of earth structures", Mercer Lecture 2011. Geotext. Geomembr. 34(2012), 51-68 (2012)

13. Tatsuoka, F., Koseki, J., Tateyama, M., Munaf, Y., Horii, N.: Seismic stability against high seismic loads of geosynthetic-reinforced soil retaining structures. Keynote Lecture, Proc. 6th Int. Conf. on Geosynthetics, Atlanta, 1: pp. 103-142 (1998)

14. Tatsuoka, F., Koseki, J., Tateyama, M.: Introduction to Japanese codes for reinforced soil design, Panel Discussion on Reinforced Soil Design Standards, Proc. 9th International Conference on Geosynthetics, Brazil, 245-255 (2010)

15. Yonezawa, T., Yamazaki, T., Tateyama, M., Tatsuoka, F.: Various geosynthetic-reinforced soil structures for Hokkaido high-speed train line, Proc. International Symposium on Design and Practice of Geosynthetic-Reinforced Soil Structures, Oct. 2013, Bologna (Ling et al., eds.), pp. 691-707 (2013)

16. Yonezawa, T., Yamazaki, T., Tateyama, M., Tatsuoka, F.: Design and construction of geosyntheticreinforced soil structures for Hokkaido high-speed train line, Transportation Geotechnics, Elsevier, Vol.1, No.1 (to appear) (2014)

17. Tatsuoka, F.: Recent practice and research of geosynthetic-reinforced earth structures in Japan. J. GeoEng. 3(3), 47-67 (2008)

18. Horii, K., Tateyama, M., Koseki, J., Tatsuoka, F.: Stability and residual deformation analyses of geosynthetic reinforced earth retaining wall with rigid facing due to large earthquakes. J. Geosynth. Eng. 13, 260-269 (in Japanese) (1998)

19. Koseki, J., Tateyama, M., Shinoda, M.: Seismic design of geosynthetic reinforced soils for railway structures in Japan, Proc. of 5th Int. Sym. on Earth Reinforcement, Fukuoka, pp. 113-119 (2007)

20. Koseki, J., Nakajima, S., Tateyama, M., Watanabe, K., Shinoda, M.: Seismic performance of geosynthetic reinforced soil retaining walls and their performance-based design in Japan, Theme Lecture, Proc. of International Conference on Performance-Based Design in Earthquake Geotechnical Engineering-from case history to practice, Tsukuba, pp. 149-161 (2009)

21. Tatsuoka, F.: Impacts on Geotechnical Engineering of several recent findings from laboratory stress-strain tests on geomaterials, 2000 Burmister Lecture at Columbia University, Geotechnics for Roads, Rail Tracks and Earth Structures (Correia \& Brandle eds.), Balkema, pp. 69-140 (2001)

22. Koseki, J., Tatsuoka, F., Munaf, Y., Tateyama, M., Kojima, K.: A modified procedure to evaluate active earth pressure at high seismic loads, Soils and Foundations, Special Issue, pp. 209-216 (1997)

23. Kongkitkul, W., Tatsuoka, F., Hirakawa, D.: Creep rupture curve for simultaneous creep deformation and degradation of geosynthetic reinforcement. Geosynth. Int. 14(4), 189-200 (2007)

24. Greenwood, J.H., Jones, C.J.F.P., Tatsuoka, F.: Residual strength and its application to design of reinforced soil in seismic areas, Proceedings of IS Kyushu (Ochia et al. eds.). Balkema 1, 37-42 (2001) 
25. Tatsuoka, F., Hirakawa, D., Shinoda, M., Kongkitkul, W., Uchimura,T.: An old but new issue; viscous properties of polymer geosynthetic reinforcement and geosynthetic-reinforced soil structures, Keynote lecture, Proc. GeoAsia04, Seoul, pp.29-77 (2004)

26. Tatsuoka, F., Kongkitkul, W., Hirakawa, D.: Viscous property and time-dependent degradation of geosynthetic reinforcement, Proc. 8th International Conference on Geosynthetics, Yokohama Vol.4, pp.1587-1590 (2006)

27. Kongkitkul, W., Hirakawa, D., Tatsuoka, F.: Viscous behaviour of geogrids; experiment and simulation. Soils Found. 47(2), 265-283 (2007)

28. Hirakawa, D., Kongkitkul, W., Tatsuoka, F., Uchimura, T.: Time-dependent stress-strain behaviour due to viscous properties of geogrid reinforcement. Geosynth. Int. 10(6), 176-199 (2003)

29. Tatsuoka, F., Tateyama, M., Mohri, Y., Matsushima, K.: Remedial treatment of soil structures using geosynthetic-reinforcing technology. Geotext. Geomembr. 25(4 \& 5), 204-220 (2007)

30. Tatsuoka, F., Tateyama, M., Koseki, J.: Performance of soil retaining walls for railway embankments, Soils and Foundations, Special Issue for the 1995 Hyogoken-Nambu Earthquake, pp.311-324 (1996)

31. Tatsuoka, F., Koseki, J., Tateyama, M.: Performance of reinforced soil structures during the 1995 Hyogoken Nanbu Earthquake, Special Lecture, International Symposium on Earth Reinforcement (IS Kyushu'96), Balkema, Vol.2, pp. 973-1008 (1997b)

32. Morishima, H., Saruya, K., Aizawa, F.: Damage to soils structures of railway and their reconstruction. Special Issue on Lessons from the 2004 Niigata-ken Chu-Etsu Earthquake and Reconstruction, Foundation Engineering and Equipment (Kiso-ko), Oct., 78-83 (in Japanese) (2005)

33. Munoz, H., Tatsuoka, F., Hirakawa, D., Nishikiori, H., Soma, R., Tateyama, M., Watanabe, K.: Dynamic stability of geosynthetic-reinforced soil integral bridge. Geosynth. Int. 19(1), 11-38 (2012)

34. Suga, M., Kuriyama, R., Tateyama, M., Kouda, M., Sugimoto, I., Kobayashi, Y.: Reinforcing method of bridge by integration of steel girder, abutment and backfill, Proc. 46th Japan Conf. on Geotechnical Engineering, JGS, Kobe, Paper No. H-06, pp. 1499-1500 (in Japanese) (2011)

35. Koda Koda, M., Nonaka, T., Suga, M., Kuriyama, R, Tateyama, M., Tatsuoka, F.: Lateral cyclic loading tests of a full-scale GRS integral bridge model, Proc. International Symposium on Design and Practice of Geosynthetic-Reinforced Soil Structures, Oct. 2013, Bologna (Ling et al., eds.), pp.157-174 (2013)

36. Yazaki, S., Tatsuoka, F., Tateyama, M., Koda, M., Watanabe, K., Duttine, A.: Seismic design of GRS integral bridge, Proc. International Symposium on Design and Practice of Geosynthetic-Reinforced Soil Structures, Oct. 2013, Bologna (Ling et al., eds.), pp. 142-156 (2013)

37. Kuriyama, R., Kojima, K., Morino, T., Watanabe, K., Aoki, H., Yamada, Y.: Behavior of geosyntheticreinforced soil integral bridge used for the Shinkansen structure, Journal of Geosynthetics Engineering, IGS Japanese Chapter, Vol.27, pp. 149-156 (in Japanese) (2012)

38. Takisawa, S., Tanino, R., Taniguchi, Y.: Damage to embankments of Iiyama Line by the Niigata Fukushima heavy rain and restoration, Proc. 47th Annual Geotechnical Symposium, Hachinohe, the JGS, pp. 1007-1008 (in Japanese) (2012)

39. Yamaguchi, S., Yanagisawa, M., Kawabe, S., Tatsuoka, F., Nihei, Y.: Evaluation of the stability of various types of coastal dyke against over-flowing tsunami current, Proc. International Symposium on Design and Practice of Geosynthetic-Reinforced Soil Structures, Oct. 2013, Bologna (Ling et al., eds.), pp. 572-581 (2013)

40. Kosa, K.: Damage analysis of bridges affected by tsunami due to Great East Japan Earthquake, Proc. International Sym. on Engineering Lessons Learned from the 2011 Great East Japan Earthquake, March, Tokyo, Japan, pp. 1386-1397 (2012)

41. Kawabe, S., Tatsuoka, F., Kuroda, T., Yamaguchi, S., Matsumaru, T., Watananbe, K., Koda, M.: Seismic stability of geosynthetic-reinforced soil integral bridge evaluated by shaking table test, Proc. International Symposium on Design and Practice of Geosynthetic-Reinforced Soil Structures, Oct. 2013, Bologna (Ling et al., eds.), pp. 126-141 (2013)

42. Kuwano, J., Koseki, J., Miyata, Y.:Performance of reinforced soil walls in the 2011 Tohoku Earthquake, Keynote lecture, Proc. 5th Asian Regional Conference on Geosynthetics, Bangkok, Thailand, pp. 85-94 (2012)

43. Tatsuoka, F.: Roles of facing rigidity in soil reinforcing, Keynote Lecture, Proc. Earth Reinforcement Practice, IS-Kyushu '92 (Ochiai et al. eds.), 2: pp. 831-870 (1992)

44. Tatsuoka, F., Tateyama, M., Koseki, J.: GRS structures recently developed and constructed for railways and roads in Japan, Keynote lecture, Proc. 2nd International Conference on Transportation Geotechnics (IS-Hokkaido 2012) (Miura et al., eds.), pp. 63-84 (2012b)

45. Tatsuoka, F.: Laboratory stress-strain tests for the development of geotechnical theories and practice, Bishop Lecture, Proc. 5th International Conference on Deformation Characteristics of Geomaterials, Seoul, Korea, Sept., pp. 3-50 (2011) 